Ophthalmology. 2008 September ; 115(9): 1447-145010. doi:10.1016/j.ophtha.2008.06.015.

\title{
A Randomized Trial Comparing Intravitreal Triamcinolone Acetonide and Focal/Grid Photocoagulation for Diabetic Macular Edema
}

\author{
Diabetic Retinopathy Clinical Research Network
}

\section{Abstract}

Objective-To evaluate the efficacy and safety of $1 \mathrm{mg}$ and $4 \mathrm{mg}$ doses of preservative-free intravitreal triamcinolone in comparison with focal/grid photocoagulation for the treatment of diabetic macular edema (DME).

\begin{abstract}
Design-Multi-center randomized clinical trial
Participants - 840 study eyes of 693 subjects with DME involving the fovea and visual acuity $20 / 40$ to $20 / 320$

Methods-Eyes were randomized to focal/grid photocoagulation ( $\mathrm{N}=330), 1 \mathrm{mg}$ intravitreal triamcinolone $(\mathrm{N}=256)$, or $4 \mathrm{mg}$ intravitreal triamcinolone $(\mathrm{N}=254)$. Retreatment was given for persistent or new edema at 4-month intervals. The primary outcome was at 2 years.
\end{abstract}
Main Outcome Measures-Visual acuity measured with the Electronic Early Treatment Diabetic Retinopathy Study (E-ETDRS) method (primary), optical coherence tomography (OCT)-measured retinal thickness (secondary), and safety.

\begin{abstract}
Results-At 4 months, mean visual acuity was better in the $4 \mathrm{mg}$ triamcinolone group than in either the laser group $(\mathrm{P}<0.001)$ or the $1 \mathrm{mg}$ triamcinolone group $(\mathrm{P}=0.001)$. By 1 year, there were no significant differences among groups in mean visual acuity. At the 16-month visit and extending through the primary outcome visit at 2 years, mean visual acuity was better in the laser group than in the other two groups (at 2 years, $\mathrm{P}=0.02$ comparing the laser and $1 \mathrm{mg}$ groups, $\mathrm{P}=0.002$ comparing the laser and $4 \mathrm{mg}$ groups, and $\mathrm{P}=0.49$ comparing the $1 \mathrm{mg}$ and $4 \mathrm{mg}$ groups). Treatment group differences in the visual acuity outcome could not be attributed solely to cataract formation. OCT results generally paralleled the visual acuity results. Intraocular pressure was increased from baseline by $\geq 10 \mathrm{~mm} \mathrm{Hg}$ at any visit in $4 \%, 16 \%$, and $33 \%$ of eyes in the three treatment groups, respectively,
\end{abstract}

Corresponding Author: Michael S. Ip, M.D., c/o Jaeb Center for Health Research, 15310 Amberly Drive, Suite 350, Tampa, FL 33647; Phone: (813) 975-8690, Fax: (800) 816-7601, drcrnetB3@ jaeb.org.

*A list of the members of the Diabetic Retinopathy Clinical Research Network participating in the trial appears in the online appendix available at http://aaojournal.org.

Conflicts of interest statement: A complete list of all DRCR.net investigator financial disclosures can be found at www.drcr.net

Writing Committee: Lead Authors: Michael S. Ip, Allison R. Edwards, Roy W. Beck, Neil M. Bressler. Additional Writing Committee Members (Alphabetical) Lloyd Paul Aiello, David J. Browning, Michael J. Elman, Scott M. Friedman, Frederick L. Ferris, Adam R. Glassman, Craig Kollman, Angela Price

This article contains online-only material. The following should appear online-only: Tables 2, 3, 6, Figure 1, and the appendix listing of the members of the Diabetic Retinopathy Clinical Research Network participating in this trial.

Publisher's Disclaimer: This is a PDF file of an unedited manuscript that has been accepted for publication. As a service to our customers we are providing this early version of the manuscript. The manuscript will undergo copyediting, typesetting, and review of the resulting proof before it is published in its final citable form. Please note that during the production process errors may be discovered which could affect the content, and all legal disclaimers that apply to the journal pertain. 
and cataract surgery was performed in $13 \%, 23 \%$, and $51 \%$ of eyes in the three treatment groups, respectively.

Conclusions-Over a 2-year period, focal/grid photocoagulation is more effective and has fewer side effects than $1 \mathrm{mg}$ or $4 \mathrm{mg}$ doses of preservative-free intravitreal triamcinolone for most patients with DME who have characteristics similar to the cohort in this clinical trial. The results of this study also support that focal/grid photocoagulation currently should be the benchmark against which other treatments are compared in clinical trials of DME.

\section{Introduction}

Macular edema is a frequent manifestation of diabetic retinopathy and an important cause of impaired vision in individuals with diabetes. ${ }^{1-3}$ The Wisconsin Epidemiologic Study of Diabetic Retinopathy (WESDR), a population-based study in southern Wisconsin, estimated that after 20 years of known diabetes, the prevalence of diabetic macular edema (DME) was approximately $28 \%$ in both type 1 and type 2 diabetes. ${ }^{1}$

The most widely accepted methods to reduce the risk of vision loss from diabetic macular edema (DME) are: (1) intensive glycemic control, as demonstrated by the Diabetes Control and Complications Trial (DCCT) ${ }^{4}$ and the United Kingdom Prospective Diabetes Study (UKPDS) ${ }^{5}$ (2) blood pressure control, as demonstrated by the UKPDS; ${ }^{6,7}$ and (3) focal/grid photocoagulation, as demonstrated by the Early Treatment Diabetic Retinopathy Study (ETDRS). ${ }^{8}$ The ETDRS reported that focal/grid photocoagulation of eyes with edema involving or threatening the fovea reduced the 3 -year risk of losing 3 or more lines of visual acuity by $50 \%$, from $30 \%$ in the control group to $15 \%$ in the laser group.

During the last decade, a number of additional treatments for DME have been proposed. Such treatments include vitrectomy, ${ }^{9-16}$ pharmacologic therapy with oral protein kinase $\mathrm{C}$ beta inhibitors ${ }^{17}$, intravitreal injection of aptamers or antibodies targeted at vascular endothelial growth factor (VEGF), ${ }^{18-20}$ and intravitreal injection of corticosteroids such as triamcinolone acetonide. In 2001-2002, the first reports were published of the use of intravitreal injection(s) of triamcinolone acetonide (hereafter referred to as intravitreal triamcinolone) for DME, 21 , 22 suggesting that intravitreal triamcinolone was potentially an efficacious treatment for DME. As a result of these reports, this treatment gained widespread use, most commonly as a dose of $4 \mathrm{mg}$ of Kenalog (Bristol-Myers Squibb, Princeton NJ), despite the lack of data from a controlled study demonstrating efficacy that exceeded risks. A 2002 Preferences and Trends Survey, conducted by the American Society of Retina Specialists showed that $52 \%$ of retina specialists surveyed that year $(\mathrm{N}=337)$ had used an intravitreal injection of triamcinolone as a treatment for DME. In 2005, the Preferences and Trends Survey showed that $91 \%$ of retina specialists surveyed that year $(\mathrm{N}=371)$ would treat a patient with intravitreal triamcinolone if cystic DME persisted despite at least 2 sessions of focal/grid photocoagulation. A multitude of case series presentations, case reports and clinical experience suggested that intravitreal triamcinolone produced a short-term reduction in macular edema and concomitant improvement in visual acuity. However, in many case series previously reported, the effects appeared to be transient, requiring repeat injections to sustain a reduction in edema. Not unexpectedly, steroid-related complications such as cataract and glaucoma have been reported in these case series. ${ }^{22-26}$

The rationale for the use of corticosteroids to treat DME follows from the observation that the increase in retinal capillary permeability that results in edema may be caused by a breakdown of the blood retina barrier mediated in part by VEGF, a $45 \mathrm{kD}$ glycoprotein. ${ }^{27-29}$ One proposed mechanism by which VEGF may induce retinal vascular permeability is through phosphorylation of the tight junctional protein occludin, resulting in the dissolution of the junctional complex. ${ }^{30,} 31$ Another mechanism entails Fas mediated endothelial cell apoptosis. 
32 The pathogenesis of retinal vascular permeability has also been attributed to inflammation, particularly through leukostasis within retinal capillaries. The attraction and adhesion of leukocytes to the vascular wall, in the setting of diabetes, may be due to an increased expression of leukocyte adhesion molecules such as retinal endothelial cell intercellular adhesion molecule-1 and CD 18. ${ }^{33-35}$ Therefore, attenuation of the effects of VEGF and a reduction in inflammation may reduce macular edema associated with diabetic retinopathy. Since corticosteroids have been demonstrated to both inhibit the expression of VEGF and the VEGF gene ${ }^{36,37}$ and to have anti-inflammatory properties, a strong rationale exists for their use in the treatment of DME.

In light of the short-term results from early reports of intravitreal triamcinolone for DME and increasingly widespread clinical use despite a lack of long-term clinical trial data, the Diabetic Retinopathy Clinical Research Network (DRCR.net) conducted a randomized clinical trial to evaluate the efficacy and safety of two doses of preservative-free intravitreal triamcinolone (1 $\mathrm{mg}$ and $4 \mathrm{mg}$ ) in comparison with standard focal/grid photocoagulation. A preservative-free preparation was used in an attempt to avoid the occurrence of post-injection ocular inflammation that has been reported with Kenalog, presumably attributable to the excipients in Kenalog, endotoxins or a particle dispersion phenomenon. ${ }^{38,} 39$

\section{Methods}

This phase 3 randomized, multi-center clinical trial was conducted by the Diabetic Retinopathy Clinical Research Network (DRCR.net) at 88 clinical sites in the United States. The study adhered to the tenets of the Declaration of Helsinki. The protocol and HIPAA-compliant informed consent forms were approved by multiple institutional review boards. Each subject gave written informed consent to participate in the study. Study oversight was provided by an independent data and safety monitoring committee. The study is listed on www.clinicaltrials.gov, under identifier NCT00367133 (website registration date August 3, 2006) and the protocol is available on the DRCR.net website (www.drcr.net, date accessed June 5, 2008). Key aspects of the protocol pertinent to this manuscript are summarized below.

\section{Study Population}

Eligible subjects were at least 18 years old with type 1 or type 2 diabetes. The major eligibility criteria for a study eye included the following: (1) best corrected electronic-ETDRS visual acuity letter score between 73 (approximately 20/40) and 24 (approximately 20/320), (2) definite retinal thickening due to DME on clinical examination involving the center of the macula assessed to be the main cause of visual loss, (3) retinal thickness measured on optical coherence tomography (OCT) $\geq 250$ microns in the central subfield (average of two measurements), and (4) no expectation for scatter photocoagulation within the next 4 months. Principal exclusion criteria included (1) prior treatment with intravitreal corticosteroids (at any time), peribulbar steroid injection within the prior 6 months, photocoagulation for DME within the prior 15 weeks, panretinal scatter photocoagulation (PRP) within the prior 4 months, or pars plana vitrectomy (at any time), (2) a history of open-angle glaucoma or steroid-induced intraocular pressure elevation that required IOP-lowering treatment, and (3) intraocular pressure $\geq 25 \mathrm{~mm} \mathrm{Hg}$. A subject could have two study eyes in the trial only if both were eligible at the time of study entry.

\section{Synopsis of Study Design}

After eligibility was determined at the clinical center and informed consent was obtained, subjects with one study eye were assigned randomly on the DRCR.net website (using a permuted blocks design stratified by visual acuity and prior photocoagulation for DME in the study eye) with equal probability to one of three treatment groups: (1) focal/grid 
photocoagulation (referred to as the laser group), (2) $1 \mathrm{mg}$ intravitreal triamcinolone (referred to as the $1 \mathrm{mg}$ triamcinolone group), or (3) $4 \mathrm{mg}$ intravitreal triamcinolone (referred to as the $4 \mathrm{mg}$ triamcinolone group). Eyes assigned to either dose of triamcinolone were not to receive focal/grid photocoagulation during follow-up unless specific failure criteria, outlined below, were reached. Photocoagulation was selected for the control group rather than a sham injection in order to compare triamcinolone treatment directly with the only ocular treatment proven to have long-term benefit for DME. For subjects with two study eyes, the right eye was randomly assigned to one of the three groups as indicated above and the left eye received the alternate treatment (focal/grid photocoagulation or randomly assigned to the $1 \mathrm{mg}$ or $4 \mathrm{mg}$ dose of triamcinolone). Thus, there were more eyes in the laser group than either the $1 \mathrm{mg}$ triamcinolone group or the $4 \mathrm{mg}$ triamcinolone group. Subjects were masked to triamcinolone dose but were not masked to focal/grid photocoagulation versus intravitreal triamcinolone assignment.

Although visual acuity testers, OCT technicians, and fundus photographers were not formally masked to treatment group, these individuals generally were not aware of the treatment group assignments.

The time point of the primary study outcome was 2 years with a secondary outcome at 3 years. Follow-up visits occurred every 4 months. Testing at each visit included measurement of best corrected visual acuity and retinal thickness on OCT. At each visit, the study eye(s) was evaluated for retreatment according to the guidelines presented below.

\section{Examination Procedures}

At baseline and at each follow-up visit, best-corrected visual acuity letter score was measured at 3 meters by a certified tester using an electronic procedure based on the ETDRS method (EETDRS). ${ }^{40}$ A standardized refraction was performed at 4, 12, 24, and 36-months. At other visits, a refraction was performed when there was a decrease in visual acuity of 15 or more letters, unless there was an obvious cause for the reduction other than macular edema, such as vitreous hemorrhage.

Following pupil dilation, OCT images were obtained at baseline (two scans were performed and the average of the two central subfield thickness measurements was used for eligibility determination and as the baseline for analysis) and at each follow-up visit by a certified operator using the Zeiss Stratus OCT (OCT3) machine (Carl Zeiss Meditech, Dublin, CA). Scans were $6 \mathrm{~mm}$ length and included the 6 radial line fast macular scan pattern for quantitative measures and the cross hair pattern (6-12 and 9-3 o'clock for qualitative assessment of retinal morphology). The OCT scans were sent to the University of Wisconsin Fundus Photograph Reading Center (Reading Center) for grading. If the automated thickness measurements were judged by the Reading Center to be inaccurate, center point thickness was measured manually, and this value was used to impute a value for the central subfield (based on a correlation of the two measures of 0.98 as published previously, ${ }^{41}$ imputation was used for $18 \%$ of scans). OCT images were also assessed for cystoid abnormalities and subretinal fluid.

Additional testing at baseline and at each follow-up visit included the following: (1) slit lamp examination, (2) fundus examination following pupil dilation, and (3) measurement of intraocular pressure with a Goldmann tonometer. Standard ETDRS 7-field color stereoscopic fundus photographs were obtained at baseline and annually by a certified photographer and graded at the reading center. ${ }^{42} \mathrm{HbA} 1 \mathrm{c}$ was measured at baseline and then annually. Any untoward medical occurrence, irrespective of whether the event was considered treatmentrelated, was considered an adverse event and recorded. Adverse events are reported through the two-year visit, or if the visit was missed, through 2 years from randomization. 


\section{Initial Treatment Protocol}

The intravitreal triamcinolone injection technique followed a standardized protocol. The triamcinolone study drug was a preservative-free preparation $(1 \mathrm{mg}$ or $4 \mathrm{mg})$ in a prefilled syringe (manufactured by Allergan, Inc., Irvine, CA). The study was conducted under an Investigational New Drug (IND) Application from the Food and Drug Administration (FDA) since this specific triamcinolone preparation was considered an investigational drug. Initially, siliconized syringes with a staked needle design were used. However, in October, 2007 after silicone oil droplets were observed in the vitreous of some eyes following injection, siliconized syringes with a Luer-cone design were used. This alteration, by increasing the residual space between the needle and the syringe, was made to reduce the amount of silicone oil injected with the triamcinolone, which was confirmed by in vitro testing performed by Allergan. Since all subjects in the triamcinolone groups had already received at least one injection with the original syringe before the change was made, we were unable to evaluate whether the change in design reduced the amount of silicone injected. The corticosteroid preparation consisted of micronized triamcinolone acetonide suspended in a hydrogel vehicle with minimal dispersive properties. Topical antibiotics were not used prior to the day of injection. On the day of the injection, topical gatifloxacin (Zymar, Allergan, Inc., Irvine, CA) was placed on the ocular surface at least 3 times over a 15 or more minute period prior to the injection. Using topical anesthesia followed by a povidone iodine prep, triamcinolone was injected into the vitreous cavity through the pars plana $3.0-4.0 \mathrm{~mm}$ posterior to the limbus. Post-injection, subjects were instructed to use gatifloxacin four times a day for three days. Safety evaluations were performed 4 days and 4 weeks after each injection. A protocol amendment on July 20, 2007 eliminated the 4-day safety evaluation based on a lack of adverse events detected at the 4-day visits and an advisory from the FDA that post-injection visits were discretionary.

The focal/grid photocoagulation technique was modified from the original ETDRS protocol as described previously and used in prior DRCR.net protocols. ${ }^{43}$ Laser photocoagulation burns were less intense (light gray instead of gray) and were limited to a smaller spot size (50 microns instead of 50-200 microns) than in the original ETDRS protocol. ${ }^{44}$ The focal/grid

photocoagulation treatment almost always was completed in a single sitting and involved direct (focal) treatment to all leaking microaneurysms and grid treatment to areas of retinal thickening and, if identified on an optional fluorescein angiogram, nonperfusion between 500 and 3000 microns from the center of the macula.

\section{Re-treatment Protocol}

At each 4-month interval visit, the investigator assessed whether persistent or recurrent DME was present that warranted retreatment. Retreatment, when indicated, was performed within four weeks after the follow-up visit (usually on the same day as the follow-up visit) and no sooner than 3.5 months from the time of the last treatment. In general, an eye was retreated unless at least one of the following deferral criteria was present, in which case retreatment was determined according to investigator judgment: (1) little or no edema involving the center of the macula and OCT central subfield $\leq 225$ microns, (2) visual acuity letter score $\geq 79(20 / 25$ or better), (3) substantial improvement in macular edema since the last treatment (e.g., $>=50 \%$ decrease in OCT central subfield thickening), (4) clinically significant adverse effect from prior treatment, (5) additional treatment "apparently futile" (defined as a less than 5 letter improvement in the visual acuity letter score or the lack of reduction in OCT central subfield thickening of at least 50 microns representing at least a $20 \%$ reduction in retinal thickening over an 8 or more month period during which two treatments [either focal/grid photocoagulation or intravitreal triamcinolone depending on randomization group] were received), and (6) for the laser group, complete focal/grid photocoagulation had already been given, with no areas identified for which additional treatment was indicated. An eye with a decrease from baseline in the best-corrected visual acuity letter score of 15 or more due to 
macular edema at two consecutive 4-month interval visits could receive an alternate treatment modality at investigator discretion (e.g., focal/grid photocoagulation for eyes assigned to a triamcinolone group or $4 \mathrm{mg}$ intravitreal triamcinolone for eyes assigned to focal/grid photocoagulation).

\section{Statistical Methods}

Visual acuity was the primary outcome measure. Two analyses were preplanned: (1) a comparison of the mean change in visual acuity among groups and (2) for regulatory purposes, a comparison of the proportion of eyes in each group with a decrease in the visual acuity letter score $\geq 15$. The protocol initially included two time points for assessing the outcome: one year and three years, with the latter being required for regulatory purposes. The protocol was subsequently amended to have the primary analysis at two years and a secondary analysis at three years after the FDA indicated that 2-year follow up might be considered sufficient for DME treatments. This report includes data collected through the two-year visit.

Sample size was estimated to be 813 eyes (approximately 689 subjects assuming $18 \%$ of subjects would have two study eyes) based on an expected population percentage of eyes with a 15 or more letter worsening of acuity of $20 \%$ in the laser group, $20 \%$ in the $1 \mathrm{mg}$ triamcinolone group, and $10 \%$ in the $4 \mathrm{mg}$ triamcinolone group; type 1 error rate of 0.049 (adjusted for alpha spending for interim data reviews); and power of approximately $90 \%$. For the outcome of the change in visual acuity letter score from baseline, with a sample size of 813 eyes and assuming a common standard deviation for the outcome visual acuity letter scores of 18 and correlation between the baseline and outcome visual acuity letter scores of 0.4 , statistical power was estimated to be $87 \%$ for detecting a mean difference in the visual acuity letter score between groups if the population difference was 5 or more.

The primary analysis included all randomized eyes and followed the intent-to-treat principle. Data were included in the two-year analysis when an examination was performed between 609 and 852 days ( 20 and 28 months) from randomization. When more than one visit occurred in this window, data from the visit closest to the two-year target date were used. For eyes without two-year data, the last-observation-carried forward method was used to impute data for the primary analysis. Similar results were produced when analyses (1) used Rubin's method ${ }^{45}$ to impute for missing data, (2) included only eyes with a completed 2-year examination, (3) were performed with truncation of outlier values to be 3 standard deviations from the mean, and (4) were performed using ranks of the visual acuity scores (instead of the actual scores) transformed to have normal distributions using van der Waerden scores (data not shown). For analyses other than the primary analysis, only data from completed visits were used with no imputation for missing data. For some results, medians and interquartile ranges have been reported instead of or in addition to means and standard deviations to describe the distribution of the data.

Three pairwise comparisons were made for all analyses. For all continuous outcomes, the treatment group comparisons were made using repeated measures analysis of covariance (ANCOVA) models accounting for correlated data from subjects with two study eyes. For binary outcomes, proportions similarly were compared between treatment groups using repeated measures generalized estimating equations (GEE) logistic regression models. All analyses included adjustment for baseline visual acuity and prior macular photocoagulation (the two variables being used to stratify randomization). In addition, models in which the central subfield thickness was the outcome included baseline central subfield thickness as a covariate and models with retinal volume as the outcome included both baseline central subfield thickness and retinal volume as covariates. For the primary analysis, a step-down Hochberg adjustment was used to account for the multiple statistical comparisons. ${ }^{46} \mathrm{~A}$ treatment by time interaction for visual acuity was tested in a longitudinal model to evaluate

Ophthalmology. Author manuscript; available in PMC 2009 September 22. 
whether treatment group differences varied from 4 months to 2 years. All $\mathrm{P}$ values are 2-sided. SAS version 9.1 (SAS Institute, Cary, NC) was used for all analyses.

\section{Results}

Between July 2004 and May 2006, 693 subjects (mean age 63 \pm 9 years; 49\% women) were enrolled, 147 (21\%) with two study eyes. The 840 study eyes with DME were randomly assigned to either focal/grid photocoagulation $(\mathrm{N}=330), 1 \mathrm{mg}$ triamcinolone $(\mathrm{N}=256)$, or $4 \mathrm{mg}$ triamcinolone $(\mathrm{N}=254)$. At baseline, the mean visual acuity letter score in study eyes was 59 \pm 11 (approximately 20/63) and the mean OCT central subfield retinal thickness was $424 \pm 130$ microns. The baseline characteristics of the three groups were similar (Table 1). Additional baseline characteristics of the cohort have been reported. ${ }^{47}$

\section{Follow Up}

The 2-year follow-up status for all study participants (eyes) is shown in Figure 1 (available at http://aaojournal.org). Thirty-three subjects (with 20,12, and 12 study eyes in the laser, $1 \mathrm{mg}$ triamcinolone and $4 \mathrm{mg}$ triamcinolone groups, respectively) died prior to the 2-year visit, from causes unrelated to study treatment. For the living subjects, the two-year visit was completed for $272(88 \%)$ of the 310 eyes in the laser group, 220 (90\%) of 244 in the $1 \mathrm{mg}$ triamcinolone group, and 205 (85\%) of 242 in the $4 \mathrm{mg}$ triamcinolone group. Baseline visual acuity was similar in the 115 subjects (143 study eyes) with incomplete 2-year follow up compared with the 578 subjects (697 eyes) who completed a 2-year visit.

\section{Treatments}

All eyes received the randomization-assigned treatment regimen at baseline, except for two eyes in the laser group and one eye in the $1 \mathrm{mg}$ triamcinolone group that were dropped from the study prior to receiving study treatment and one eye in the laser group that received a $4 \mathrm{mg}$ triamcinolone injection. Among those completing the two-year visit, the mean number of treatments with the assigned treatment regimen prior to the two-year visit was 2.9 in the laser group, 3.5 in the $1 \mathrm{mg}$ triamcinolone group, and 3.1 in the $4 \mathrm{mg}$ triamcinolone group, with 2.1, 2.3 , and 2.1, respectively being given prior to the one-year visit (Table 2 available at http://aaojournal.org).

Prior to the 2-year visit, treatment for DME other than the randomly assigned treatment was received by 43 (13\%) eyes in the laser group, 46 (18\%) eyes in the $1 \mathrm{mg}$ triamcinolone group, and 34 eyes (13\%) in the $4 \mathrm{mg}$ triamcinolone group. Eighteen eyes (5\%) in the laser group received $4 \mathrm{mg}$ intravitreal triamcinolone, 25 eyes (10\%) in the $1 \mathrm{mg}$ triamcinolone group received focal/grid photocoagulation, and 20 eyes (8\%) in the $4 \mathrm{mg}$ triamcinolone group received focal/grid photocoagulation due to persistent edema and reduced visual acuity. A vitrectomy was performed because of macular traction thought to be exacerbating the DME in $18(5 \%), 14(5 \%)$, and $10(4 \%)$ eyes in the three groups, respectively, and an intravitreal injection of an anti-VEGF drug was given to $6(2 \%), 5(2 \%)$, and $5(2 \%)$ eyes in the three groups, respectively.

\section{Effect of Treatment on Visual Acuity}

The differences in treatment effect among the three groups varied over time $(\mathrm{P}<0.001$ for interaction between time and treatment group). At 4 months, mean visual acuity was better in the $4 \mathrm{mg}$ triamcinolone group than in the laser group (mean difference adjusted for baseline visual acuity and prior macular photocoagulation $=+3.8,95 \%$ confidence interval $=+1.8$ to $+5.8, \mathrm{P}<0.001$ ) and the $1 \mathrm{mg}$ triamcinolone group (mean difference adjusted for baseline visual acuity and prior macular photocoagulation $=+3.6,95 \%$ confidence interval $=+1.4$ to +5.8 , $\mathrm{P}=0.001$ ). By 1 year, there were no significant differences in visual acuity among groups. 
Beginning with the 16-month visit and extending through the primary outcome visit at 2 years, the laser group showed a greater beneficial effect on visual acuity compared with the two triamcinolone groups, which were similar to each other (Table 3 available at http://aaojournal.org, Figure 2).

For the two-year primary outcome, the mean change in the visual acuity letter score from baseline was $+1 \pm 17$ in the laser group, $-2 \pm 18$ in the $1 \mathrm{mg}$ triamcinolone group, and $-3 \pm 22$ in the $4 \mathrm{mg}$ triamcinolone group (for the 32 -group comparisons, mean difference adjusted for baseline visual acuity and prior macular photocoagulation, $95 \%$ confidence interval, and $\mathrm{p}$ value were as follows: laser versus $1 \mathrm{mg}$ triamcinolone $=+3.5$, [ +0.6 to +6.4$], \mathrm{P}=0.02$; laser versus $4 \mathrm{mg}$ triamcinolone $=+4.6,[+1.7$ to +7.5$], \mathrm{P}=0.002 ; 1 \mathrm{mg}$ triamcinolone versus $4 \mathrm{mg}$ triamcinolone: $=+1.1,[-2.1$ to +4.3$], \mathrm{P}=0.49$; Table 4$)$. A worsening of the visual acuity letter score of 15 or more occurred in $14 \%, 20 \%$, and $20 \%$ of the three groups, respectively $(\mathrm{P}=0.03$, $0.01,0.82$, respectively for the three pairwise comparisons listed above), and an improvement in the visual acuity letter score by 15 or more occurred in $18 \%, 14 \%$, and $17 \%$ of the three groups, respectively $(\mathrm{P}=0.10,0.48$, and 0.36 , respectively for the three pairwise comparisons listed above).

Limiting the analysis to eyes that were pseudophakic at baseline, mean change from baseline to 2 years in the visual acuity letter score was $+2 \pm 18$ in the laser group ( $N=54),+2 \pm 17$ in the $1 \mathrm{mg}$ triamcinolone group $(\mathrm{N}=48)$, and $-1 \pm 19$ in the $4 \mathrm{mg}$ triamcinolone group $(\mathrm{N}=43)$. When the analysis included eyes that were pseudophakic or had minimal or no cataract by clinician assessment at 2 years, mean change from baseline to 2 years in the visual acuity letter score was $+3 \pm 16$ in the laser group ( $\mathrm{N}=178), 0 \pm 18$ in $1 \mathrm{mg}$ triamcinolone group $(\mathrm{N}=136)$, and $0 \pm 22$ in the $4 \mathrm{mg}$ triamcinolone group $(\mathrm{N}=159)$.

There was no evidence of substantially different results in subgroups of sufficient size based on baseline visual acuity, baseline OCT-measured central subfield thickening, and history of prior focal/grid photocoagulation for DME (Table 5).

There were 72 subjects who had one eye assigned to the laser group and one eye in the $1 \mathrm{mg}$ triamcinolone group and 75 subjects who had one eye in the laser group and one eye in the 4 $\mathrm{mg}$ triamcinolone group. For the laser-1 $\mathrm{mg}$ triamcinolone subjects, the mean paired difference in change in visual acuity letter score at 2 years was 4.4 (95\% confidence interval -0.2 to 9.0 ) and for the laser- $4 \mathrm{mg}$ triamcinolone subjects the mean paired difference was 4.5 (95\% confidence interval -1.4 to 10.3), in each case favoring the laser group.

\section{Effect of Treatment on Retinal Thickening}

The OCT results generally paralleled the visual acuity results, with a greater beneficial effect seen at the 4-month visit in the $4 \mathrm{mg}$ triamcinolone group compared with the other two groups, a greater beneficial effect in the laser group compared with the other two groups during the second year, and no difference between the two triamcinolone groups during the second year (Table 6 available at http://aaojournal.org-, Figure 3). OCT central subfield thickness decreased from baseline to 2 years by a mean of $139 \pm 148$ microns in the laser group, $86 \pm 167$ microns in the $1 \mathrm{mg}$ triamcinolone group ( $\mathrm{P}<0.001$ compared with the laser group), and $77 \pm 160$ microns in the $4 \mathrm{mg}$ triamcinolone group $(\mathrm{P}<0.001$ compared with the laser group and 0.91 compared with the $1 \mathrm{mg}$ triamcinolone group); $67 \%, 46 \%$, and $48 \%$ of eyes respectively had a decrease in retinal thickening of $50 \%$ or more $(\mathrm{P}<0.001,<0.001$, and $=0.60$ respectively for the three pairwise comparisons), and 53\%, 34\%, and 38\% had central subfield thickness $<250$ microns ( $\mathrm{P}<0.001,<0.001$ and $=0.55$ respectively for the three pairwise comparisons). A tendency for a greater reduction in OCT-measured retinal thickening in the laser group than in the triamcinolone groups was present irrespective of the degree of retinal thickening at baseline 
(Table 7). Results were similar comparing the change in OCT-measured retinal volume among treatment groups (Table 7).

\section{Adverse Events}

Major ocular adverse events are summarized in Table 8. There were no cases of endophthalmitis or inflammatory pseudoendophthalmitis following any of the 1649 intravitreal injections (1583 in study eyes in the triamcinolone groups, 23 in study eyes in the laser group, and 43 in nonstudy eyes). Silicone oil droplets were noted in 77 (30\%) eyes in the $1 \mathrm{mg}$ triamcinolone group (841 injections given) and 59 (23\%) eyes in the $4 \mathrm{mg}$ triamcinolone group (742 injections given). Although some subjects were symptomatic with floaters, there was no indication of an adverse effect of the silicone oil on the eye. There were no systemic adverse events with a difference in frequency among the three groups that could not be attributed to chance.

With regard to ocular hypertension and glaucoma, there were more eyes in the $4 \mathrm{mg}$ triamcinolone group (40\%) than in the $1 \mathrm{mg}$ triamcinolone group (20\%) or laser group (10\%) that had one of the following at one or more visits: (1) elevation in intraocular pressure $\geq 10$ $\mathrm{mm} \mathrm{Hg}$ from baseline, (2) intraocular pressure $\geq 30 \mathrm{~mm} \mathrm{Hg}$, (3) initiation of intraocular pressure-lowering medications (if not being treated at study entry), or a diagnosis of glaucoma $(\mathrm{P}<0.001$ for all three pairwise comparisons). Glaucoma surgery was performed in four eyes in the $4 \mathrm{mg}$ triamcinolone group (filtering procedure in two, laser trabeculoplasty in one, and ciliary body destruction in one). At the two-year visit, mean intraocular pressure was $16 \mathrm{~mm}$ $\mathrm{Hg}$ in all groups; treatment to lower intraocular pressure was being used by $3 \%, 6 \%$, and $13 \%$ of eyes in the laser, $1 \mathrm{mg}$ triamcinolone and $4 \mathrm{mg}$ triamcinolone groups, respectively.

Among phakic eyes at baseline, cataract surgery was performed prior to the 2-year outcome visit in more eyes in the $4 \mathrm{mg}$ triamcinolone group (51\%) than in the $1 \mathrm{mg}$ triamcinolone group $(23 \%)$ or in the laser group $(13 \%)(\mathrm{P}<0.001$ for all three pairwise comparisons).

There were no differences among groups in the change of $\mathrm{HbAlc}$ from baseline to one year or two years (data not shown).

\section{Discussion}

This phase 3 randomized clinical trial compared $1 \mathrm{mg}$ and $4 \mathrm{mg}$ doses of preservative-free triamcinolone with focal/grid photocoagulation as treatments for eyes with DME and visual acuity ranging from 20/40 to 20/320. At 4 months, a greater positive treatment response on visual acuity was seen in the $4 \mathrm{mg}$ triamcinolone group compared with the other two groups. However, by 1 year, there was little difference in visual acuity between the groups, and at the time of the two-year primary outcome assessment, visual acuity and safety (with respect to intraocular pressure and cataract) were significantly better in the laser group than in either the $4 \mathrm{mg}$ triamcinolone or $1 \mathrm{mg}$ triamcinolone groups. There was no significant difference between the $1 \mathrm{mg}$ triamcinolone and $4 \mathrm{mg}$ triamcinolone groups in visual acuity at 2 years. Treatment group differences in the change in retinal thickening generally mirrored the effect on visual acuity, with initially a greater reduction in the $4 \mathrm{mg}$ triamcinolone group, an eventual greater reduction in the laser group, and no difference between the two triamcinolone groups at 2 years.

The lesser efficacy of triamcinolone on visual acuity relative to focal/grid photocoagulation at two years is unlikely to be on the basis of corticosteroid-induced lens changes alone, in view of the OCT results and since an analysis limited to eyes that were pseudophakic or without lens changes judged clinically relevant did not demonstrate a benefit of triamcinolone compared with focal/grid photocoagulation. Likewise, a benefit of triamcinolone relative to photocoagulation was not seen in prespecified subgroups of sufficient size based on baseline 
visual acuity, retinal thickening, or a history of prior macular photocoagulation. Among the small number of eyes with the most severe visual acuity loss at baseline (20/200 to 20/320), most of the eyes in the $4 \mathrm{mg}$ triamcinolone group had an improvement in visual acuity at 2 years. However, the number of such eyes was too small $(\mathrm{N}=13)$ for a meaningful assessment of the treatment effect relative to focal/grid photocoagulation.

With respect to the safety of the intravitreal injections, through two years of follow up, there were no cases of infectious or noninfectious endophthalmitis following an injection of the preservative-free triamcinolone preparation used in this study. A relatively high incidence of detection of silicone oil droplets in the vitreous following intravitreal injections (about a quarter of eyes treated with intravitreal triamcinolone) was noted. This is a recognized occurrence after intravitreal injection using siliconized syringes. ${ }^{48}$ Although some subjects were symptomatic from floaters due to the silicone oil droplets, we have not identified any adverse effects on the eye attributable to the silicone oil. Consistent with other reports, ${ }^{22,}, 49,50$ the $4 \mathrm{mg}$ triamcinolone injections were associated with an increased incidence of both elevation of intraocular pressure and development of cataract requiring surgery. Most cases of elevated intraocular pressure were adequately controlled with ocular hypotensive medications, but in the $4 \mathrm{mg}$ triamcinolone group, two cases required a filtering procedure, one case required a laser trabeculoplasty, and one case required a ciliary body destructive procedure.

The $4 \mathrm{mg}$ triamcinolone dose was evaluated because it was the dose most commonly used in clinical practice at the time the trial was initiated. The $1 \mathrm{mg}$ dose was included because this dose was likely to exceed the concentration necessary to saturate the glucocorticoid receptors in the cell cytoplasm completely. ${ }^{51,52}$ Also, it was hoped that adverse effects on the lens and intraocular pressure might be less frequent. Indeed, the $1 \mathrm{mg}$ triamcinolone group had fewer side effects with respect to glaucoma and cataract than the $4 \mathrm{mg}$ triamcinolone group. Although the $4 \mathrm{mg}$ group was superior to the $1 \mathrm{mg}$ group with respect to vision at 4 months and superior to the $1 \mathrm{mg}$ group with respect to retinal thickening up to 1 year, no difference in visual acuity or retinal thickening was detected after 2 years of follow up. The retreatment protocol encouraged frequent reinjection, with reinjection of triamcinolone at 4-month intervals as long as edema was present, visual acuity or retinal thickening had not improved substantially since the last injection, futility criteria were not met (see methods), or an adverse event such as increased intraocular pressure had not occurred that precluded retreatment at that visit. The occurrence of elevated intraocular pressure may have limited the number of reinjections in some subjects. The early treatment effect of triamcinolone relative to focal/grid photocoagulation found in the current study is consistent with many published case series ${ }^{50}$, 53,54 and a small randomized trial showing such an effect. ${ }^{55}$ One other small randomized trial reported no significant difference comparing focal/grid photocoagulation and $4 \mathrm{mg}$ intravitreal triamcinolone after 4 months or 12 months. ${ }^{49}$

The trial had a sample size that was sufficiently large so that it is highly unlikely that a true 2year benefit of triamcinolone over focal/grid photocoagulation went undetected, particularly since the results favored the photocoagulation group. The treatment groups were well balanced with regard to baseline factors. Although investigators and subjects were not masked to treatment group with respect to photocoagulation versus triamcinolone, it is unlikely that this was a source of bias favoring the photocoagulation group, since the prestudy presumption was that intravitreal triamcinolone might be a better treatment than focal/grid photocoagulation. Visual acuity was measured using a computerized system and OCT scans were graded at a reading center masked to treatment group, reducing the potential for bias in these assessments. The consistency between the visual acuity and OCT results adds further credence to the validity of the findings. The study completion rate of $83 \%$ ( $88 \%$ if deaths are excluded) was lower than expected, but we have no indication that this significantly influenced the results. The 
completion rate was similar among the treatment groups and analyses using three different methods for handling missing data produced similar results.

Based on data from the ETDRS, it appears likely that the visual acuity outcome with each of the three treatment regimens is superior to the expected untreated course. The best estimate of the untreated course of visual acuity in eyes with DME for comparison with the treatment groups in the current study comes from the treatment group in the ETDRS in which focal/grid photocoagulation was deferred. Among 235 ETDRS eyes in that group that had definite center thickening on fundus photographs, a visual acuity letter score $<74$ [worse than 20/32], and mild to moderate nonproliferative retinopathy at baseline, the median visual acuity letter score at two years was decreased from baseline by -6 , with $12 \%$ improving 10 or more letters and $43 \%$ worsening 10 or more letters (unpublished data, provided by Frederick L. Ferris, M.D.). This was a substantially worse outcome than observed in any of our three treatment groups. It is important to note that in the current study, some eyes had more severe retinopathy than those included in this analysis of ETDRS data. Further support for the positive long-term effect on visual acuity and retinal thickening of intravitreal triamcinolone comes from a randomized trial conducted by Gillies et al. ${ }^{50}$ These authors reported a beneficial effect on visual acuity and retinal thickening of $4 \mathrm{mg}$ intravitreal triamcinolone compared with sham injections after 2 years of follow up in a randomized trial involving 69 eyes of 43 subjects previously treated with focal/grid photocoagulation with persistent DME and visual acuity 20/30 or worse. The conclusions from the Gillies study cannot be directly compared with the conclusions from the current study because only about half of the control group eyes in the Gillies study received focal/grid photocoagulation during the study, and collectively these eyes fared much worse than the laser group in the current study.

The results of the current study elevate the importance of focal/grid photocoagulation in managing DME, across a wide range of visual acuities and a wide range of retinal thicknesses, even in eyes with prior macular photocoagulation for DME. It is important to note that eyes with prior macular photocoagulation were enrolled in this trial only if judged by the investigator to have the potential to benefit from additional laser treatment. Although the ETDRS demonstrated that focal/grid photocoagulation improves the visual outcome of DME, it has been largely believed that the benefit was in reducing the frequency of vision loss and not in improving visual acuity. However, this general conclusion ignores the fact that the majority of eyes in the ETDRS had normal or near normal visual acuity and thus did not have the potential for substantial visual acuity improvement. In a subset of 114 ETDRS eyes meeting the aforementioned criteria that were treated with immediate focal/grid photocoagulation, the results were similar to the findings in the current study. This ETDRS subset of eyes had a median change in the visual acuity letter score from baseline to two years of +4 , with $29 \%$ improving 10 or more letters and $16 \%$ worsening 10 or more letters (unpublished data, provided by Frederick L. Ferris, M.D.). A prior DRCR.net study evaluating macular photocoagulation regimens also demonstrated that visual acuity improvement is not uncommon after focal/grid photocoagulation for DME. ${ }^{43}$ In the 46 eyes in that study with a baseline visual acuity letter score $\leq 73$ (20/40 or worse) and central subfield thickness $\geq 250$ microns that were in the focal/ grid photocoagulation group, the median change in the visual acuity letter score from baseline to one year was +6 , with $37 \%$ of eyes improving 10 or more letters and $9 \%$ worsening 10 or more letters (unpublished data). With respect to any deleterious effects of focal/grid photocoagulation on visual acuity, there has been no indication of an attenuation of the beneficial effect of photocoagulation through 2 years of follow up. Results from the ETDRS $^{8}$ focal/grid photocoagulation group showing no deterioration of visual acuity through 3 years support the expectation that deterioration of visual acuity will not be seen during the third year of follow up in the current study. The fact that photocoagulation was administered by a wide range of treating physicians in the DRCR Network based on a written protocol 
without grading of photographs to confirm adherence to protocol enhances the generalizability of the study results.

The photocoagulation treatment regimen utilized in the current study, which was a modification of the regimen used in the ETDRS, encouraged frequent retreatment at 4-month intervals whenever there was persistent or new edema that had not been previously treated and had not improved substantially since the last treatment. In view of the importance of focal/grid photocoagulation in treating DME, as re-affirmed by this study, additional studies are needed to develop a better understanding of when photocoagulation treatment is complete and the optimal time interval for repeating treatment. To this end, the DRCR.net is currently conducting a study evaluating whether a less intensive photocoagulation retreatment algorithm offers enough promise to warrant a clinical trial comparing such treatment to the more intensive retreatment criteria used in this study. Pending such a study, it is not known whether a less aggressive approach of deferring retreatment with focal/grid photocoagulation as long as there is evidence of improvement in visual acuity or retinal thickening might produce results similar to the current study.

Although the results of the current study confirm the ETDRS finding that focal/grid photocoagulation has a substantial beneficial effect on DME, there is certainly a role for better treatments in the future, since about half of the study eyes in the photocoagulation group still had central retinal thickening at two years, with about one in five having worsened 10 or more letters from baseline and only about one in three having improved by 10 or more letters. The fact that the $4 \mathrm{mg}$ intravitreal triamcinolone group had a greater positive treatment response on visual acuity and retinal thickening at 4 months while the photocoagulation group had a greater positive response later raises the possibility that combining focal/grid photocoagulation with intravitreal triamcinolone might produce greater benefit for DME than either focal/grid photocoagulation or intravitreal triamcinolone alone. A DRCR.net study is currently evaluating a combination of intravitreal triamcinolone and focal/grid photocoagulation, a combination of ranibizumab and photocoagulation, and ranibizumab alone, in eyes with characteristics similar to those included in the current study (protocol available at www.drcr.net, date accessed June $5,2008)$.

In conclusion, although intravitreal triamcinolone likely improves visual acuity over two years compared with the expected untreated course, the results of our study demonstrate that focal/ grid photocoagulation is not only more effective over at least 2 years than intravitreal triamcinolone with respect to both visual acuity and OCT-measured retinal thickening, but also is associated with far fewer adverse events, particularly elevation of intraocular pressure and lens changes. Based on these results, the strongest scientific evidence currently supports focal/ grid photocoagulation as the most effective treatment for patients with DME who have similar characteristics to the cohort in this clinical trial. The results of this study also support that focal/ grid photocoagulation currently should be the benchmark against which other treatments are compared in clinical trials of DME.

\section{Supplementary Material}

Refer to Web version on PubMed Central for supplementary material.

\section{Acknowledgments}

Financial Support: Supported through a cooperative agreement from the National Eye Institute and the National Institute of Diabetes and Digestive and Kidney Diseases, National Institutes of Health, Department of Health and Human Services EY14231, EY14269, EY14229 
The funding organization participated in oversight of the conduct of the study and review of the manuscript but not directly in the design of the study, the conduct of the study, data collection, data management, data analysis, interpretation of the data, or preparation of the manuscript.

Allergan, Inc. provided the triamcinolone and topical antibiotics after successfully competing for a request for proposals issued by DRCR.net for a company to provide a preservative-free triamcinolone for the study. As per the DRCR.net Industry Collaboration Guidelines (available at www.drcr.net), the DRCR.net had complete control over the design of the protocol, ownership of the data, and all editorial content of presentations and publications related to the protocol. Allergan, Inc. has provided unrestricted funds to DRCR.net for its discretionary use.

\section{References}

1. Klein R, Klein BE, Moss SE, et al. The Wisconsin Epidemiologic Study of Diabetic Retinopathy. IV. Diabetic macular edema. Ophthalmology 1984;91:1464-74. [PubMed: 6521986]

2. Moss SE, Klein R, Klein BE. Ten-year incidence of visual loss in a diabetic population. Ophthalmology 1994;101:1061-70. [PubMed: 8008348]

3. Moss SE, Klein R, Klein BE. The 14-year incidence of visual loss in a diabetic population. Ophthalmology 1998;105:998-1003. [PubMed: 9627648]

4. Diabetes Control and Complication Trial Research Group. The effect of intensive treatment of diabetes on the development and progression of long-term complications in insulin-dependent diabetes mellitus. N Engl J Med 1993;329:977-86. [PubMed: 8366922]

5. UK Prospective Diabetes Study (UKPDS) Group. Intensive blood-glucose control with sulphonylureas or insulin compared with conventional treatment and risk of complications in patients with type 2 diabetes (UKPDS 33). Lancet 1998;352:837-53. [PubMed: 9742976]

6. Gray A, Clarke P, Farmer A, Holman R, United Kingdom Prospective Diabetes Study (UKPDS) Group. Implementing intensive control of blood glucose concentration and blood pressure in type 2 diabetes in England: cost analysis (UKPDS 63). BMJ 2002;325:860. [PubMed: 12386035]

7. Stratton IM, Cull CA, Adler AI, et al. Additive effects of glycaemia and blood pressure exposure on risk of complications in type 2 diabetes: a prospective observational study (UKPDS 75). Diabetologia 2006;49:1761-9. [PubMed: 16736131]

8. Early Treatment Diabetic Retinopathy Study Research Group. Photocoagulation for diabetic macular edema. Early Treatment Diabetic Retinopathy Study report number 1. Arch Ophthalmol 1985;103:1796-806. [PubMed: 2866759]

9. Lewis H, Abrams GW, Blumenkranz MS, Campo RV. Vitrectomy for diabetic macular traction and edema associated with posterior hyaloidal traction. Ophthalmology 1992;99:753-9. [PubMed: 1594222]

10. Harbour JW, Smiddy WE, Flynn HW Jr, Rubsamen PE. Vitrectomy for diabetic macular edema associated with a thickened and taut posterior hyaloid membrane. Am J Ophthalmol 1996;121:40513. [PubMed: 8604734]

11. Tachi N, Ogino N. Vitrectomy for diffuse macular edema in cases of diabetic retinopathy. Am J Ophthalmol 1996;122:258-60. [PubMed: 8694095]

12. Pendergast SD, Hassan TS, Williams GA, et al. Vitrectomy for diffuse diabetic macular edema associated with a taut premacular posterior hyaloid. Am J Ophthalmol 2000;130:178-86. [PubMed: 11004291]

13. Ikeda T, Sato K, Katano T, Hayashi Y. Vitrectomy for cystoid macular oedema with attached posterior hyaloid membrane in patient with diabetes. Br J Ophthalmol 1999;83:12-4. [PubMed: 10209427]

14. Yamamoto T, Akabane N, Takeuchi S. Vitrectomy for diabetic macular edema: the role of posterior vitreous detachment and epimacular membrane. Am J Ophthalmol 2001;132:369-77. [PubMed: 11530050]

15. Hartley KL, Smiddy WE, Flynn HW Jr, Murray TG. Pars plana vitrectomy with internal limiting membrane peeling for diabetic macular edema. Retina 2008;28:410-9. [PubMed: 18327132]

16. Figueroa MS, Contreras I, Noval S. Surgical and anatomical outcomes of pars plana vitrectomy for diffuse nontractional diabetic macular edema. Retina 2008;28:420-6. [PubMed: 18327133]

17. PKC-DMES Study Group. Effect of ruboxistaurin in patients with diabetic macular edema: thirtymonth results of the randomized PKC-DMES clinical trial. Arch Ophthalmol 2007;125:318-24. [PubMed: 17353401] 
18. Nguyen QD, Tatlipinar S, Shah SM, et al. Vascular endothelial growth factor is a critical stimulus for diabetic macular edema. Am J Ophthalmol 2006;142:961-9. [PubMed: 17046701]

19. Chun DW, Heier JS, Topping TM, et al. A pilot study of multiple intravitreal injections of ranibizumab in patients with center-involving clinically significant diabetic macular edema. Ophthalmology 2006;113:1706-12. [PubMed: 17011952]

20. Macugen Diabetic Retinopathy Study Group. A phase II randomized double-masked trial of pegaptanib, an anti-vascular endothelial growth factor aptamer, for diabetic macular edema. Ophthalmology 2005;112:1747-57. [PubMed: 16154196]

21. Jonas JB, Sofker A. Intraocular injection of crystalline cortisone as adjunctive treatment of diabetic macular edema. Am J Ophthalmol 2001;132:425-7. [PubMed: 11530068]

22. Martidis A, Duker JS, Greenberg PB, et al. Intravitreal triamcinolone for refractory diabetic macular edema. Ophthalmology 2002;109:920-7. [PubMed: 11986098]

23. Jonas JB, Kreissig I, Degenring R. Intraocular pressure after intravitreal injection of triamcinolone acetonide. Br J Ophthalmol 2003;87:24-7. [PubMed: 12488256]

24. Jonas J, Heatley G, Spaide R, Varma R. Intravitreal triamcinolone acetonide and secondary ocular hypertension. J Glaucoma 2005;14:168-71. [PubMed: 15741821]

25. Jonas JB, Degenring RF, Kreissig I, et al. Intraocular pressure elevation after intravitreal triamcinolone acetonide injection. Ophthalmology 2005;112:593-8. [PubMed: 15808249]

26. Jonas JB, Degenring R, Vossmerbaeumer U, Kamppeter B. Frequency of cataract surgery after intravitreal injection of high-dosage triamcinolone acetonide. Eur J Ophthalmol 2005;15:462-4. [PubMed: 16001378]

27. Aiello LP, Bursell SE, Clermont A, et al. Vascular endothelial growth factor-induced retinal permeability is mediated by protein kinase $\mathrm{C}$ in vivo and suppressed by an orally effective betaisoform-selective inhibitor. Diabetes 1997;46:1473-80. [PubMed: 9287049]

28. Antonetti DA, Barber AJ, Hollinger LA, et al. Vascular endothelial growth factor induces rapid phosphorylation of tight junction proteins occludin and zonula occluden: 1. A potential mechanism for vascular permeability in diabetic retinopaty and tumors. J Biol Chem 1999;274:23463-7. [PubMed: 10438525]

29. Senger DR, Galli SJ, Dvorak AM, et al. Tumor cells secrete a vascular permeability factor that promotes accumulation of ascites fluid. Science 1983;219:983-5. [PubMed: 6823562]

30. Antonetti DA, Barber AJ, Khin S, et al. Penn State Retina Research Group. Vascular permeability in experimental diabetes is associated with reduced endothelial occludin content: vascular endothelial growth factor decreases occludin in retinal endothelial cells. Diabetes 1998;47:1953-9. [PubMed: 9836530]

31. Barber AJ, Antonetti DA. Mapping the blood vessels with paracellular permeability in the retinas of diabetic rats. Invest Ophthalmol Vis Sci 2003;44:5410-6. [PubMed: 14638745]

32. Joussen AM, Poulaki V, Mitsiades N, et al. Suppression of Fas-FasL-induced endothelial cell apoptosis prevents diabetic blood-retinal barrier breakdown in a model of streptozotocin-induced diabetes. FASEB J 2003;17:76-8. [PubMed: 12475915]

33. Miyamoto K, Khosrof S, Bursell SE, et al. Prevention of leukostasis and vascular leakage in streptozotocin-induced diabetic retinopathy via intercellular adhesion molecule-1 inhibition. Proc Natl Acad Sci U S A 1999;96:10836-41. [PubMed: 10485912]

34. Kern TS. Contributions of inflammatory processes to the development of the early stages of diabetic retinopathy. Exp Diabetes Res 2007;2007:95103. [PubMed: 18274606]

35. Joussen AM, Poulaki V, Le ML, et al. A central role for inflammation in the pathogenesis of diabetic retinopathy. FASEB J 2004;18:1450-2. [PubMed: 15231732]

36. Nauck M, Karakiulakis G, Perruchoud A, et al. Corticosteriods inhibit the expression of the vascular endothelial growth factor gene in human vascular smooth muscle cells. Euro J Pharmacol 1998;341:309-15.

37. Nauck M, Roth M, Tamm M, et al. Induction of vascular endothelial growth factor by plateletactivating factor and platelet-derived growth factor is downregulated by corticosteroids. Am J Respir Cell Mol Biol 1997;16:398-406. [PubMed: 9115750]

38. Chen SD, Lochhead J, Patel CK. Diffuse intraocular dispersion of triamcinolone particles as a cause of sterile endophthalmitis [letter]. Arch Ophthalmol 2004;122:1733. [PubMed: 15534152] 
39. Moshfeghi DM, Kaiser PK, Bakri SJ, et al. Presumed sterile endophthalmitis following intravitreal triamcinolone acetonide injection. Ophthalmic Surg Lasers Imaging 2005;36:24-9. [PubMed: 15688968]

40. Beck RW, Moke PS, Turpin AH, et al. A computerized method of visual acuity testing: adaptation of the Early Treatment of Diabetic Retinopathy Study testing protocol. Am J Ophthalmol 2003;135:194-205. [PubMed: 12566024]

41. Diabetic Retinopathy Clinical Research Network. Relationship between optical coherence tomography-measured central retinal thickness and visual acuity in diabetic macular edema. Ophthalmology 2007;114:525-36. [PubMed: 17123615]

42. Early Treatment Diabetic Retinopathy Study Research Group. Fundus photographic risk factors for progression of diabetic retinopathy: ETDRS report number 12. Ophthalmology 1991;98(suppl):82333. [PubMed: 2062515]

43. Writing Committee for the Diabetic Retinopathy Clinical Research Network. Comparison of the modified Early Treatment Diabetic Retinopathy Study and mild macular grid laser photocoagulation strategies for diabetic macular edema. Arch Ophthalmol 2007;125:469-80. [PubMed: 17420366]

44. Early Treatment Diabetic Retinopathy Study Research Group. Treatment techniques and clinical guidelines for photocoagulation of diabetic macular edema: Early Treatment Diabetic Retinopathy Study report number 2. Ophthalmology 1987;94:761-74. [PubMed: 3658348]

45. Little, RJA.; Rubin, DB. Wiley series in probability and mathematical statistics. New York: Wiley; 1987. Statistical Analysis with Missing Data; p. xx-xx.AQ: provide specific inclusive pagination for material being cited

46. Hochberg Y. A sharper Bonferroni procedure for multiple tests of significance. Biometrika 1988;75:800-2.

47. Ip MS, Bressler SB, Antoszyk AN, et al. A randomized trial comparing intravitreal triamcinolone and laser photocoagulation for diabetic macular edema: baseline features. Retina. In Press. AQ: cannot verify without preprints; in press articles are not listed on journal website

48. Freund KB, Laud K, Eandi CM, Spaide RF. Silicone oil droplets following intravitreal injection. Retina 2006;26:701-3. [PubMed: 16829818]

49. Ockrim ZK, Sivaprasad S, Falk S, et al. Intravitreal triamcinolone versus laser photocoagulation for persistent diabetic macular oedema. Br J Ophthalmol 2008;92:795-9. [PubMed: 18420749]

50. Gillies MC, Sutter FK, Simpson JM, et al. Intravitreal triamcinolone for refractory diabetic macular edema: two-year results of a double-masked, placebo-controlled, randomized clinical trial. Ophthalmology 2006;113:1533-8. [PubMed: 16828501]

51. Then Bergh F, Grasser A, Trenkwalder C, et al. Binding characteristics of the glucocorticoid receptor in peripheral blood lymphocytes in multiple sclerosis. J Neurol 1999;246:292-8. [PubMed: 10367698]

52. Schottelius A, Wedel S, Weltrich R, et al. Higher expression of glucocorticoid receptor in peripheral mononuclear cells in inflammatory bowel disease. Am J Gastroenterol 2000;95:1994-9. [PubMed: 10950048]

53. Massin P, Audren F, Haouchine B, et al. Intravitreal triamcinolone acetonide for diabetic diffuse macular edema: preliminary results of a prospective controlled trial. Ophthalmology 2004;111:21824. [PubMed: 15019365]

54. Lam DS, Chan CK, Mohamed S, et al. Intravitreal triamcinolone plus sequential grid laser versus triamcinolone or laser alone for treating diabetic macular edema: six-month outcomes. Ophthalmology 2007;114:2162-7. [PubMed: 17459479]

55. Avitabile T, Longo A, Reibaldi A. Intravitreal triamcinolone compared with macular laser grid photocoagulation for the treatment of cystoid macular edema. Am J Ophthalmol 2005;140:695-702. [PubMed: 16226521] 


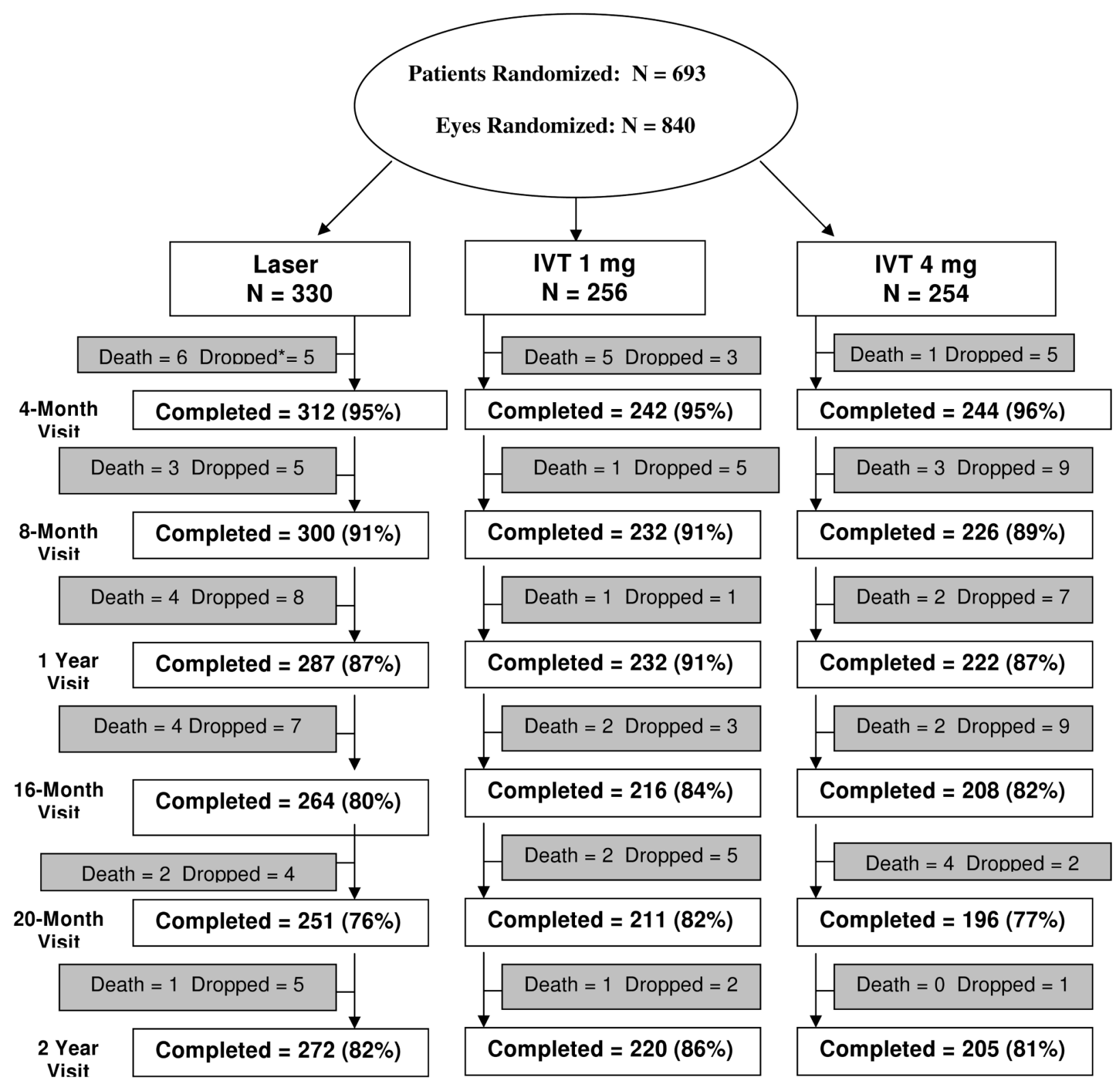

*Dropped $=$ Withdrew or Lost to Follow

Note: Ns differ from tables 3 and 6 due to not all testing being completed at every visit.

Figure 1.

Flow chart showing visit completion rate according to treatment group over the two years of follow up. 


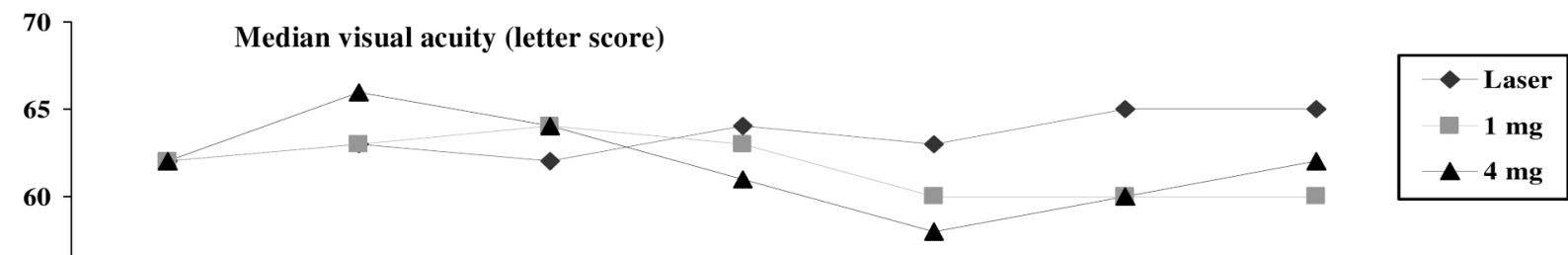

55
50

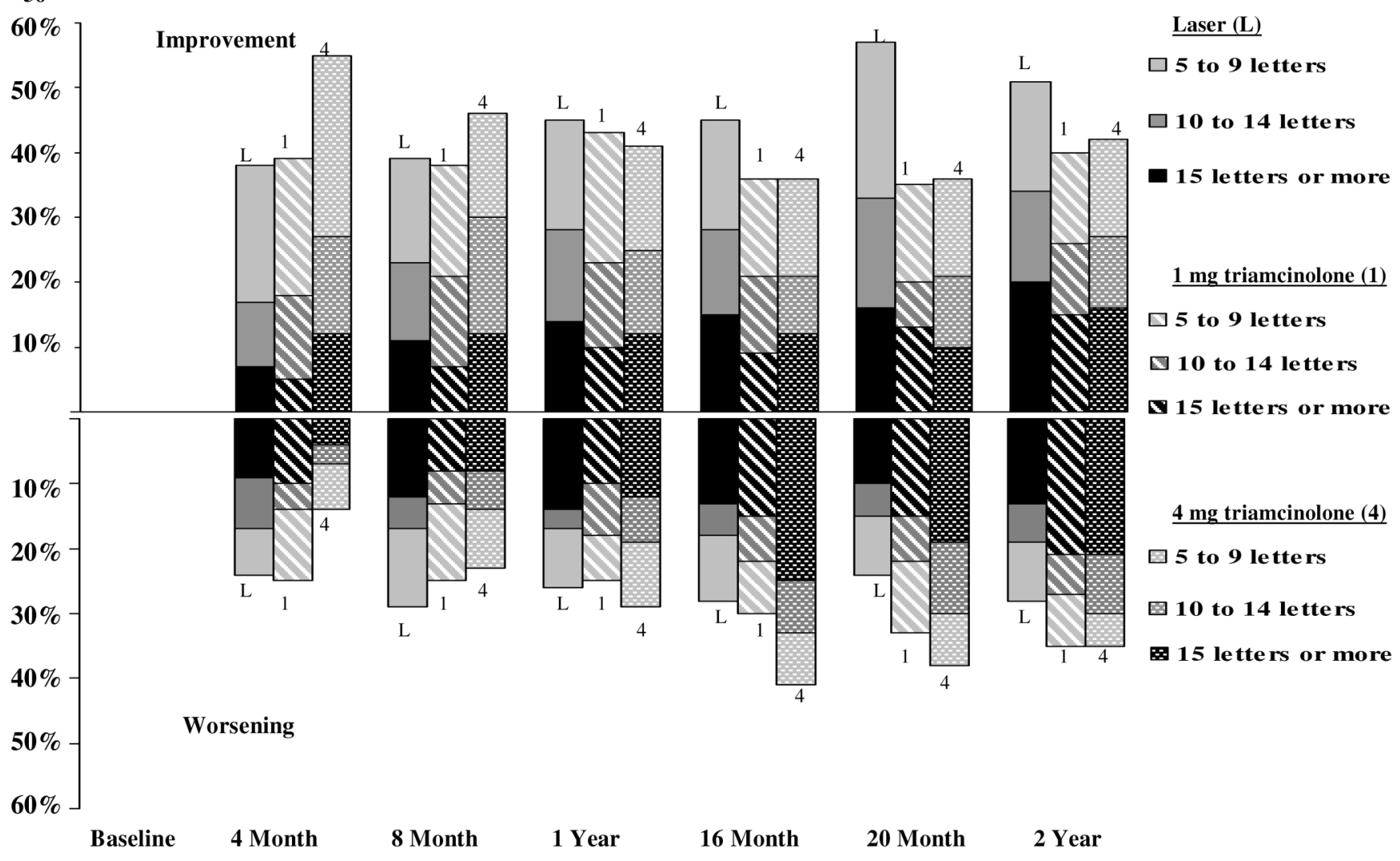

Figure 2.

Change in visual acuity from baseline to each visit through 2 years according to treatment group. The top portion of the figure displays the median visual acuity in each treatment group. In the bottom portion, the top bars represent the percentage of eyes in each treatment group (solid is laser group [L], striped is $1 \mathrm{mg}$ triamcinolone group [1], dotted is $4 \mathrm{mg}$ triamcinolone group [4]) with an improvement in the visual acuity letter score of 5 to 9 (black segments), 10 to 14 (dark gray segments), and 15 or more (light gray segments); the bottom bars represent the proportion of eyes in each treatment group (solid is laser group [L], striped is $1 \mathrm{mg}$ triamcinolone group [1], dotted is $4 \mathrm{mg}$ triamcinolone group [4]) with a worsening in the visual acuity letter score of 5 to 9 (black segments), 10 to 14 (dark gray segments), and 15 or more (light gray segments). 


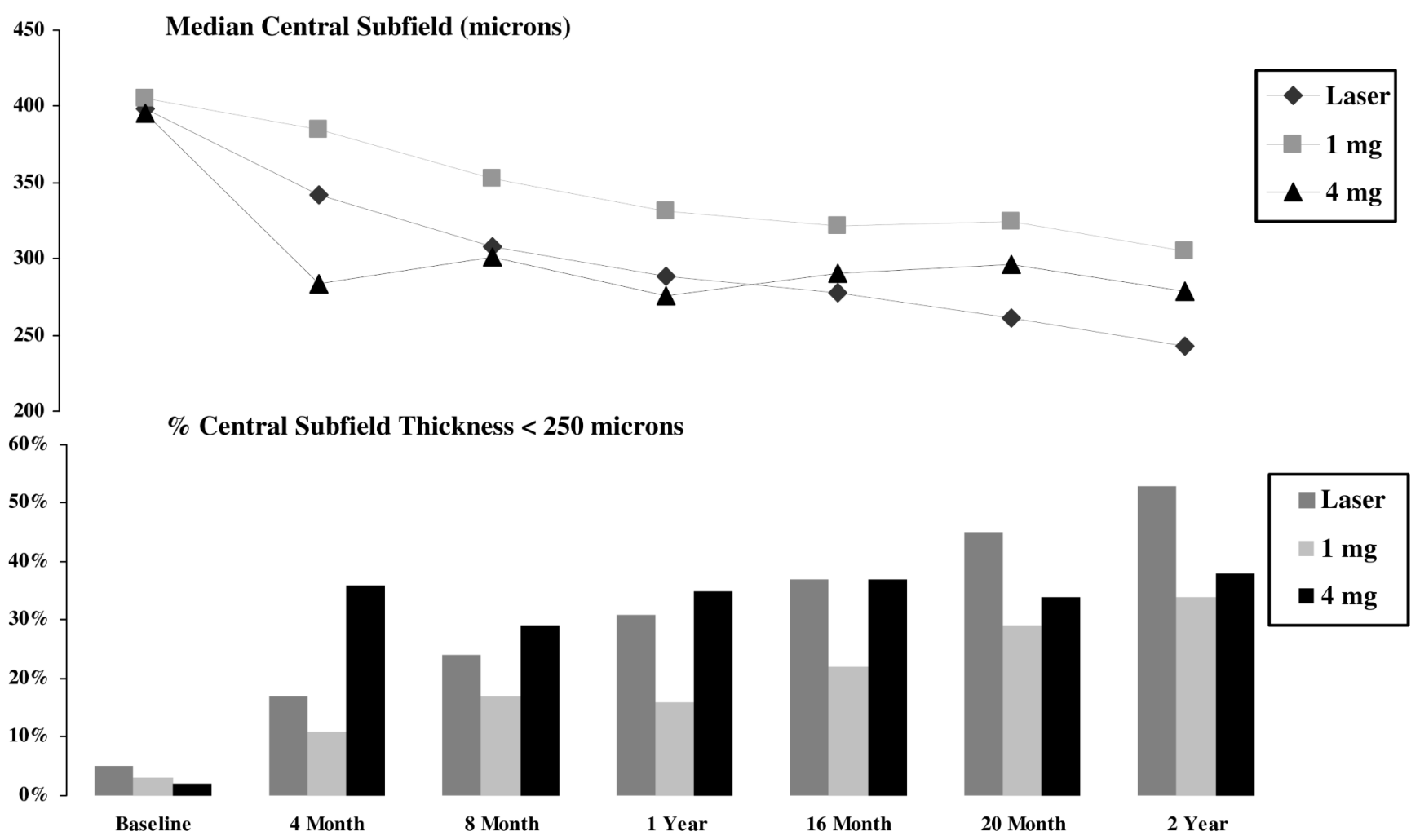

Figure 3.

Effect of treatment on the central subfield thickness, measured with optical coherence tomography (OCT), at each visit according to treatment group. The top portion of the figure displays the median thickness in each treatment group. The bars in the bottom portion represent the proportion of eyes in each treatment group with thickness $<250$ microns. 
Table 1

Baseline Subject Characteristics According to Treatment Group

\begin{tabular}{|c|c|c|c|}
\hline & $\begin{array}{c}\text { Laser } \\
\mathbf{N}=\mathbf{3 3 0} \text { eyes }\end{array}$ & $\begin{array}{l}1 \mathrm{mg} \\
\mathrm{N}=256 \text { eyes }\end{array}$ & $\begin{array}{c}4 \mathrm{mg} \\
\mathrm{N}=254 \text { eyes }\end{array}$ \\
\hline Gender: Women - N(\%) & $166(50 \%)$ & $120(47 \%)$ & $125(49 \%)$ \\
\hline Age $(\mathbf{y r s})-$ Median $\left(25^{\text {th }}, 75^{\text {th }}\right.$ percentile $)$ & $63(57,69)$ & $63(58,70)$ & $63(57,69)$ \\
\hline \multicolumn{4}{|l|}{ Race- N(\%) } \\
\hline White & $243(74 \%)$ & $186(73 \%)$ & $183(72 \%)$ \\
\hline African-American & $31(9 \%)$ & $22(9 \%)$ & $26(10 \%)$ \\
\hline Hispanic or Latino & $39(12 \%)$ & $34(13 \%)$ & $33(13 \%)$ \\
\hline Asian & $7(2 \%)$ & $8(3 \%)$ & $5(2 \%)$ \\
\hline American Indian/Alaskan Native & $2(1 \%)$ & $2(1 \%)$ & $2(1 \%)$ \\
\hline Native Hawaiian/Other Pacific Islander & $1(<1 \%)$ & 0 & $1(<1 \%)$ \\
\hline More than one race & $1(<1 \%)$ & $1(<1 \%)$ & 0 \\
\hline Unknown/not reported & $6(2 \%)$ & $3(1 \%)$ & $4(2 \%)$ \\
\hline \multicolumn{4}{|l|}{ Diabetes Type- N(\%) } \\
\hline Type 1 & $14(4 \%)$ & $12(5 \%)$ & $12(5 \%)$ \\
\hline Type 2 & $316(96 \%)$ & $244(95 \%)$ & $242(95 \%)$ \\
\hline Duration of Diabetes (yrs)- Median $\left(25^{\text {th }}, 75^{\text {th }}\right.$ percentile $)$ & $15(9,21)$ & $15(9,21)$ & $16(10,22)$ \\
\hline HbA1c ${ }^{*}-$ Median $\left(25^{\text {th }}, 75^{\text {th }}\right.$ percentile $)$ & $7.5(6.6,8.5)$ & $7.5(6.8,8.4)$ & $7.6(6.8,8.8)$ \\
\hline $\begin{array}{l}\text { Prior photocoagulation for Diabetic Macular Edema - } \\
\mathrm{N}(\%)\end{array}$ & $198(60 \%)$ & $154(60 \%)$ & $158(62 \%)$ \\
\hline Prior Panretinal Scatter Photocoagulation - N(\%) & $53(16 \%)$ & $40(16 \%)$ & $42(17 \%)$ \\
\hline $\begin{array}{l}\text { Intraocular Pressure (mmHg)-Median }\left(25^{\text {th }}, 75^{\text {th }}\right. \\
\text { percentile) }\end{array}$ & $16(13,18)$ & $16(13,18)$ & $16(14,18)$ \\
\hline History of Ocular Hypertension $-\mathrm{N}(\%)$ & $3(1 \%)$ & $8(3 \%)$ & $4(2 \%)$ \\
\hline Lens Status Phakic (clinical exam) - N(\%) & $262(79 \%)$ & $203(79 \%)$ & $197(78 \%)$ \\
\hline \multicolumn{4}{|l|}{$\begin{array}{l}\text { Baseline Electronic Early Treatment Diabetic Retinopathy } \\
\text { Study (E-ETDRS) Visual Acuity (letter score) }\end{array}$} \\
\hline Median (25th, 75 th percentile) & $62(53,67)$ & $62(54,67)$ & $62(52,67)$ \\
\hline \multicolumn{4}{|l|}{ Randomization Strata- N(\%) } \\
\hline $73-60(20 / 40$ to $20 / 63)$ & $189(57 \%)$ & $149(58 \%)$ & $149(59 \%)$ \\
\hline $59-36(<20 / 63$ to $>20 / 200)$ & $129(39 \%)$ & $94(37 \%)$ & $92(36 \%)$ \\
\hline $35-24(20 / 200$ to $20 / 320)$ & $12(4 \%)$ & $13(5 \%)$ & $13(5 \%)$ \\
\hline $\begin{array}{l}\text { Central Subfield Thickness(microns) on Optical } \\
\text { Coherence Tomography (OCT) -Median }\left(25^{\text {th }}, 75^{\text {th }}\right. \\
\text { percentile) })^{\dagger+} \xi\end{array}$ & $398(329,505)$ & $405(327,514)$ & $396(323,484)$ \\
\hline $\begin{array}{l}\text { Retinal Volume }\left(\mathbf{m m}^{3}\right) \text { on OCT -Median }\left(25^{\text {th }}, 75^{\text {th }}\right. \\
\text { percentile })^{\dagger \neq}\end{array}$ & $9.2(7.9,10.6)$ & $8.9(7.8,10.5)$ & $8.9(7.9,10.0)$ \\
\hline $\begin{array}{l}\text { OCT Cystoid Abnormality (questionable or definite)- N } \\
(\%)^{\dagger}\end{array}$ & $315(96 \%)$ & $243(96 \%)$ & $246(98 \%)$ \\
\hline $\begin{array}{l}\text { OCT Subretinal Fluid Present (questionable or } \\
\text { definite)- } \mathrm{N}(\%)^{\dagger / /}\end{array}$ & $94(29 \%)$ & $64(25 \%)$ & $61(24 \%)$ \\
\hline \multicolumn{4}{|l|}{ Retinopathy Severity (ETDRS Severity Scale)-N $(\%)^{\dagger}$} \\
\hline Microaneurysms only (level 20) & $1(<1 \%)$ & $1(<1 \%)$ & 0 \\
\hline $\begin{array}{l}\text { Mild to moderately severe non-proliferative (level } 35,43 \text {, } \\
\text { 47) }\end{array}$ & $186(58 \%)$ & $156(63 \%)$ & $151(62 \%)$ \\
\hline
\end{tabular}




\begin{tabular}{lccc}
\hline & $\begin{array}{c}\text { Laser } \\
\text { N=330 eyes }\end{array}$ & $\begin{array}{c}\mathbf{1} \mathbf{~ m g} \\
\text { N=256 eyes }\end{array}$ & $\begin{array}{c}\mathbf{4} \mathbf{~ m g} \\
\text { N=254 eyes }\end{array}$ \\
\hline Severe non-proliferative (level 53) & $43(14 \%)$ & $27(11 \%)$ & $25(10 \%)$ \\
Mild to moderate proliferative (level 60, 61, 65) & $79(25 \%)$ & $56(23 \%)$ & $62(25 \%)$ \\
High risk proliferative (level 71, 75) & $9(3 \%)$ & $8(3 \%)$ & $6(2 \%)$ \\
\hline
\end{tabular}

Subjects with two study eyes are counted in one of the triamcinolone groups and in the laser group.

*

Missing HbA1c data in 64, 46, and 50 in the laser, $1 \mathrm{mg}$, and $4 \mathrm{mg}$ groups respectively

${ }^{\dagger}$ Missing (or ungradeable) OCT and fundus photograph data as follows for the laser, $1 \mathrm{mg}$, and $4 \mathrm{mg}$ groups respectively: central subfield $(1,2,1)$, retinal volume $(47,36,48)$, cystoid abnormality $(3,4,2)$, subretinal fluid $(1,4,1)$, retinopathy severity $(12,8,10)$.

mean of two baseline scans

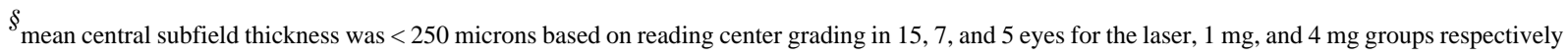
"within center or outside of center 
Table 2

Number of Treatments with Randomization Assigned Treatment

\begin{tabular}{|c|c|c|c|}
\hline & Laser & $1 \mathrm{mg}$ & $4 \mathrm{mg}$ \\
\hline & $N=272$ & $\mathrm{~N}=\mathbf{2 2 0}$ & $\mathrm{N}=\mathbf{2 0 5}$ \\
\hline \multicolumn{4}{|l|}{ Baseline to $<1$ Year ${ }^{*}$} \\
\hline Baseline only $N(\%)$ & $69(25 \%)$ & $34(15 \%)$ & $51(25 \%)$ \\
\hline Baseline +4 mos only $N(\%)$ & $76(28 \%)$ & $56(25 \%)$ & $44(21 \%)$ \\
\hline Baseline $+8 \operatorname{mos}$ only $N(\%)$ & $22(8 \%)$ & $22(10 \%)$ & $43(21 \%)$ \\
\hline $4 \operatorname{mos}+8$ mos only $N(\%)$ & $1(<1 \%)$ & 0 & 0 \\
\hline Baseline $+4 \operatorname{mos}+8 \operatorname{mos} N(\%)$ & $104(38 \%)$ & $108(49 \%)$ & $67(33 \%)$ \\
\hline Mean \pm Standard Deviation (SD) & $2.1 \pm 0.8$ & $2.3 \pm 0.7$ & $2.1 \pm 0.8$ \\
\hline \multicolumn{4}{|l|}{ Total Number Baseline to <2 Years } \\
\hline 1 & $52(19 \%)$ & $25(11 \%)$ & $25(12 \%)$ \\
\hline 2 & $65(24 \%)$ & $36(16 \%)$ & $52(25 \%)$ \\
\hline 3 & $67(25 \%)$ & $54(25 \%)$ & $49(24 \%)$ \\
\hline 4 & $49(18 \%)$ & $46(21 \%)$ & $39(19 \%)$ \\
\hline 5 & $28(10 \%)$ & $31(14 \%)$ & $27(13 \%)$ \\
\hline 6 & $11(4 \%)$ & $28(13 \%)$ & $13(6 \%)$ \\
\hline Mean \pm SD & $2.9 \pm 1.4$ & $3.5 \pm 1.5$ & $3.1 \pm 1.4$ \\
\hline
\end{tabular}

Table includes only subjects completing the 2-year visit.

*

too many permutations to detail beyond 8 months 
Page 22

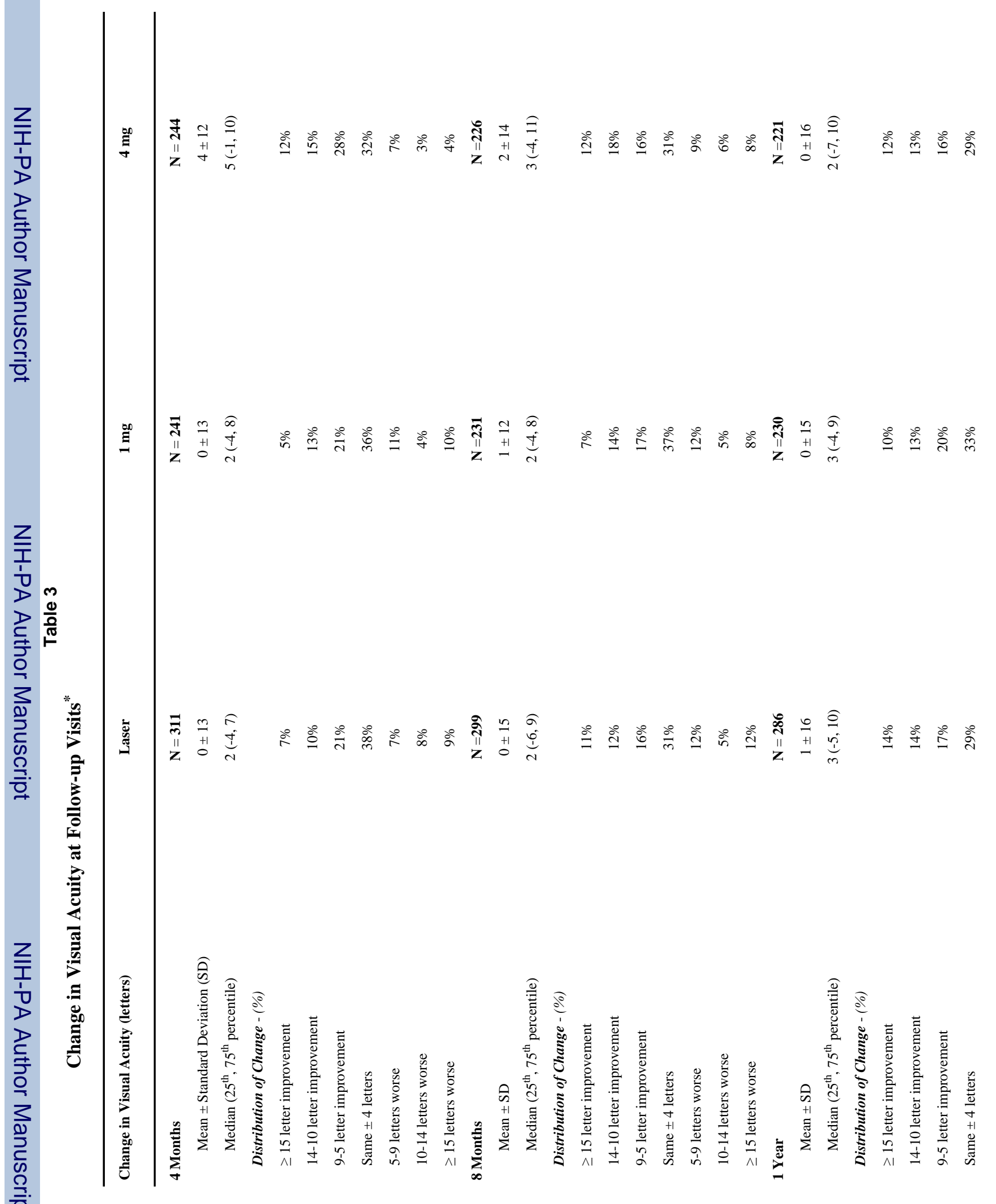


Page 23

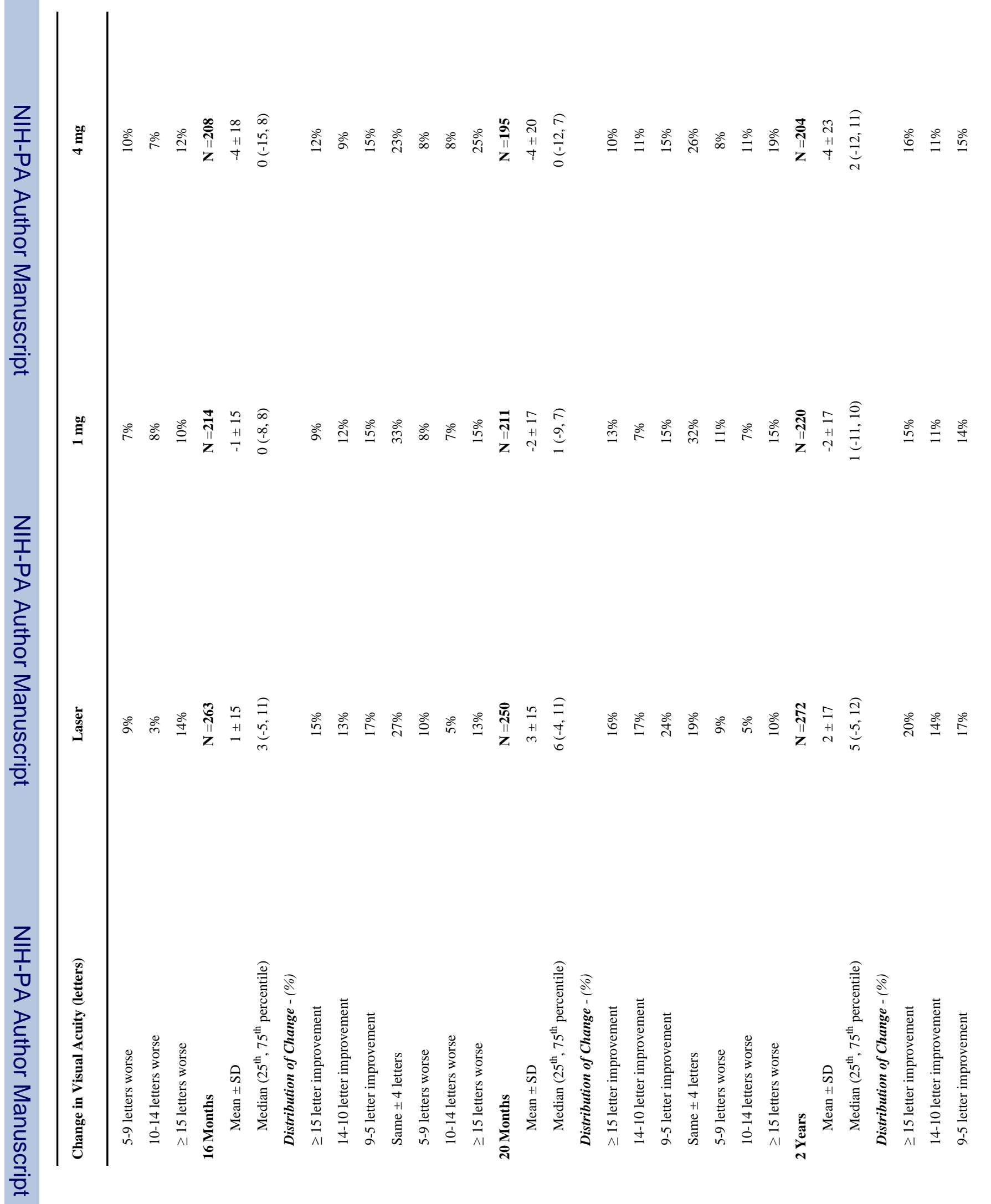


Page 24

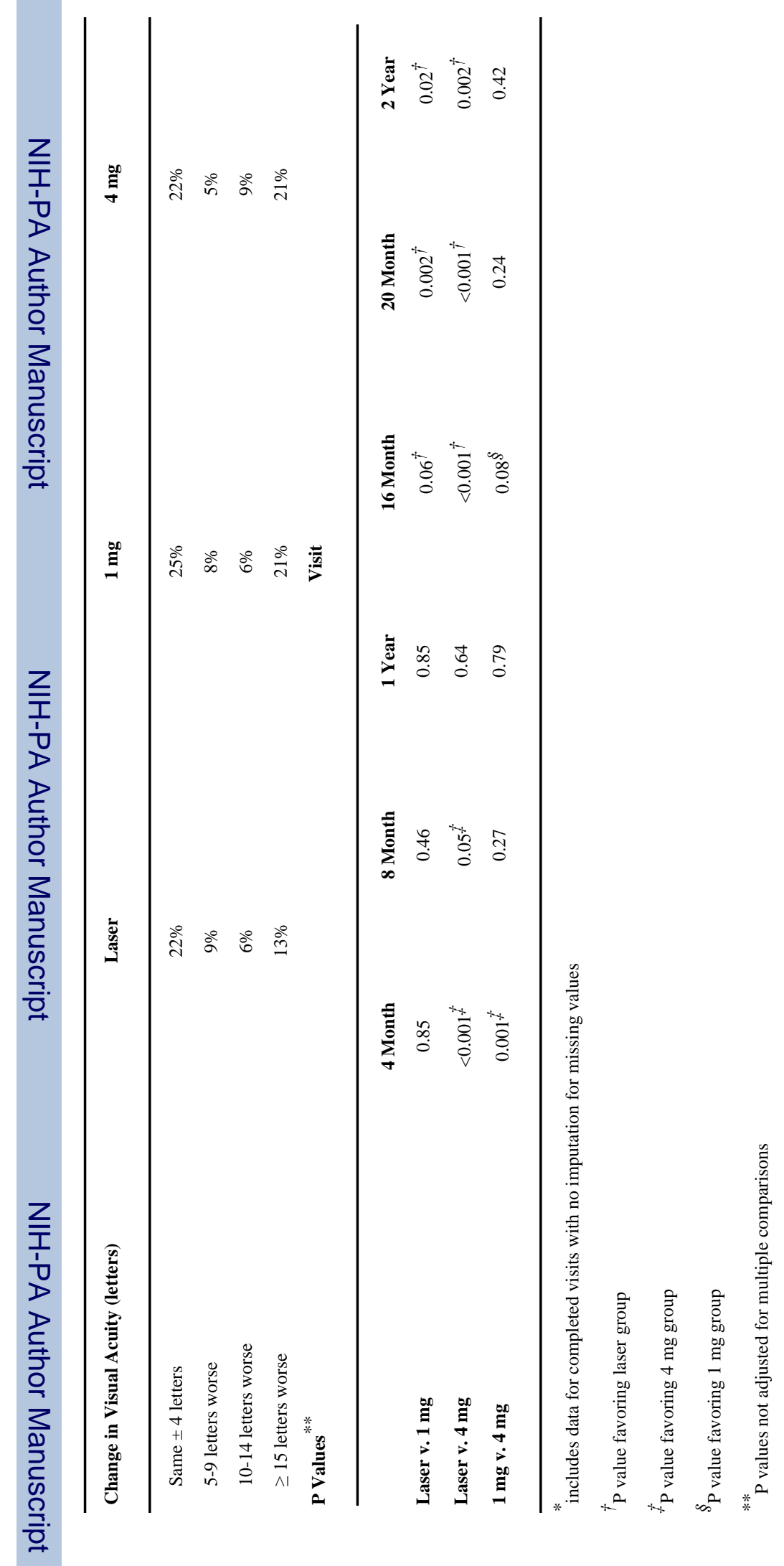

Ophthalmology. Author manuscript; available in PMC 2009 September 22. 
Table 4

Change in Visual Acuity at 2 Year Primary Outcome*

\begin{tabular}{|c|c|c|c|}
\hline Change in Visual Acuity (letters) & $\begin{array}{c}\text { Laser } \\
\mathbf{N}=330\end{array}$ & $\underset{N=256}{1} \mathbf{~ m g}$ & $\begin{array}{c}4 \mathrm{mg} \\
\mathrm{N}=254\end{array}$ \\
\hline Mean \pm Standard Deviation $(\mathrm{SD})$ & $1 \pm 17$ & $-2 \pm 18$ & $-3 \pm 22$ \\
\hline Median $\left(25^{\text {th }}, 75^{\text {th }}\right.$ percentile $)$ & $4(-6,11)$ & $1(-11,9)$ & $2(-11,11)$ \\
\hline \multicolumn{4}{|c|}{ Distribution of Change at 2 Years - (\%) } \\
\hline$\geq 15$ letter improvement & $18 \%$ & $14 \%$ & $17 \%$ \\
\hline 14-10 letter improvement & $13 \%$ & $11 \%$ & $11 \%$ \\
\hline 9-5 letter improvement & $16 \%$ & $14 \%$ & $15 \%$ \\
\hline Same \pm 4 letters & $24 \%$ & $27 \%$ & $23 \%$ \\
\hline 5-9 letters worse & $10 \%$ & $9 \%$ & $6 \%$ \\
\hline 10-14 letters worse & $5 \%$ & $6 \%$ & $8 \%$ \\
\hline$\geq 15$ letters worse & $14 \%$ & $20 \%$ & $20 \%$ \\
\hline
\end{tabular}

* Visits occurring between 609 and 852 days from randomization were included as 2-year visits. When more than one visit occurred in this window, data from the visit closest to the two-year target date were used. For other eyes without any 2-year data (58 eyes in the laser group, 36 eyes in the 1 mg triamcinolone group, and 50 eyes in the $4 \mathrm{mg}$ triamcinolone group), the last-observation-carried forward method was used to impute data for the primary analysis. Refraction was performed prior to the best corrected visual acuity measurement used in this analysis in $89 \%, 86 \%, 88 \%$ of eyes in the laser, 1 $\mathrm{mg}$ triamcinolone, and $4 \mathrm{mg}$ triamcinolone groups, respectively. For other eyes, a refraction from the prior visit was used.

$\mathrm{P}$ values for two-group comparisons of difference in mean change: laser v. $1 \mathrm{mg}=0.02$, laser v. $4 \mathrm{mg}=0.002,1 \mathrm{mg} \mathrm{v} .4 \mathrm{mg}=0.49$

$\mathrm{P}$ values for two-group comparisons of proportion with 15 or more letter worsening: laser v. $1 \mathrm{mg}=0.03,1$ aser $\mathrm{v} .4 \mathrm{mg}=0.01,1 \mathrm{mg} \mathrm{v} .4 \mathrm{mg}=0.82$

Hochberg's procedure was used to determine statistical significance by the following prespecified plan. After ordering the p-values of the 3 comparisons from highest to lowest ( $1>$ p2 > p3), statistical significance is determined as follows: If p1 $\leq 0.049$ (includes an adjustment of 0.001 to account for DSMC data reviews), all comparisons are considered statistically significant; otherwise, if p $2 \leq(0.049 / 2)=0.0245$ then p 2 and p 3 are considered statistically significant; otherwise, if $\mathrm{p} 3 \leq(0.049 / 3)=0.0163$ then it will be considered statistically significant. 


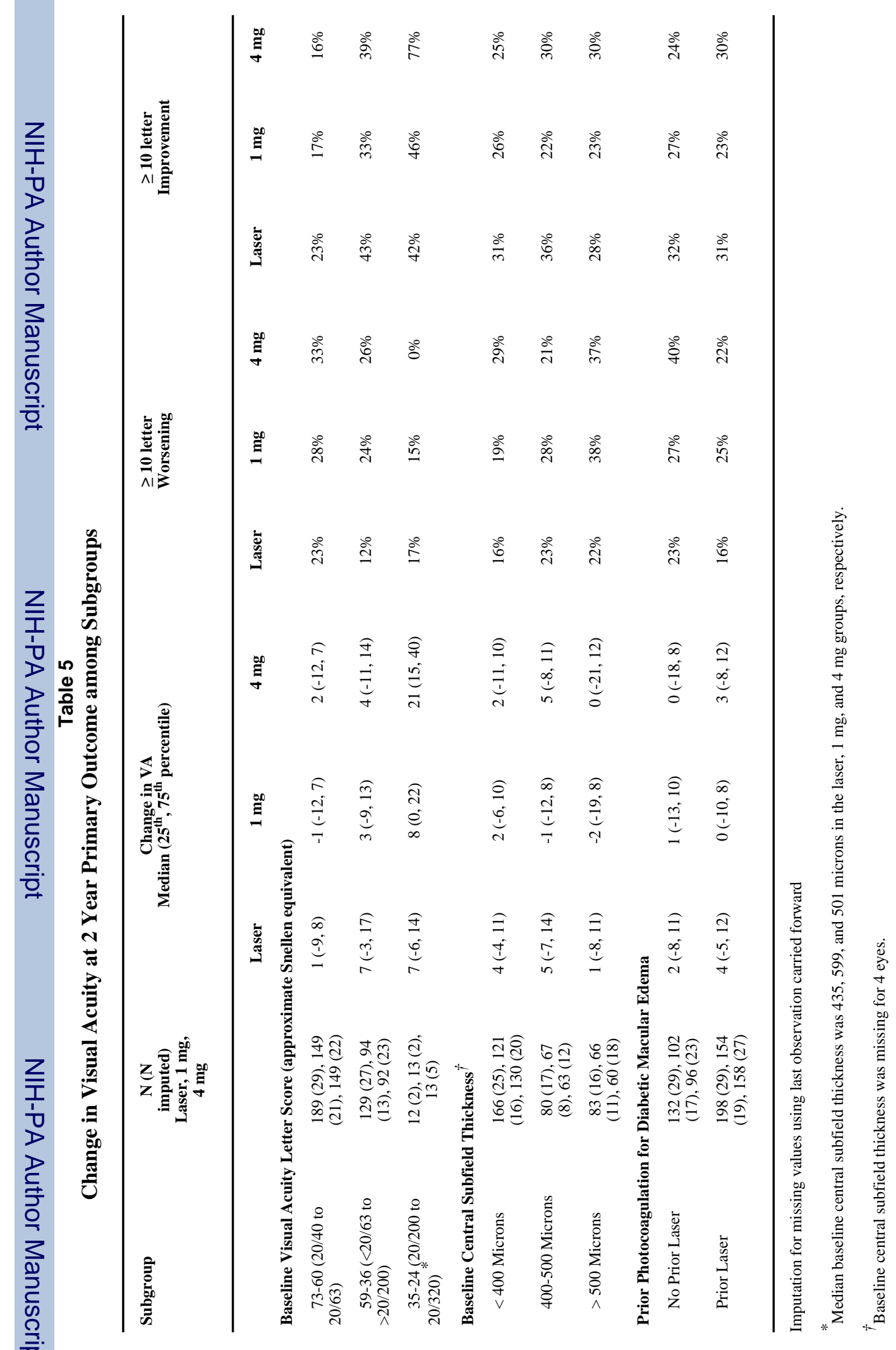




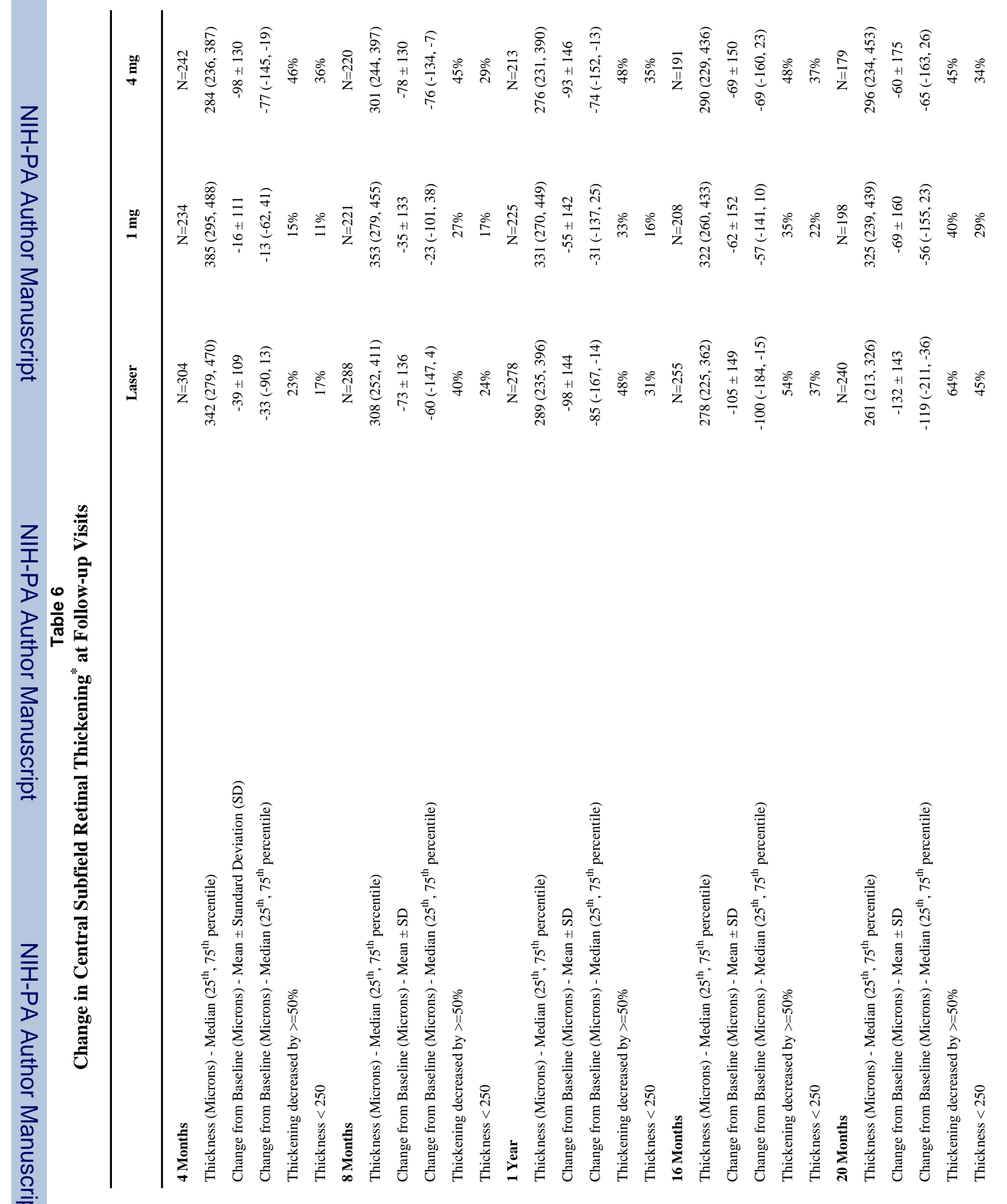




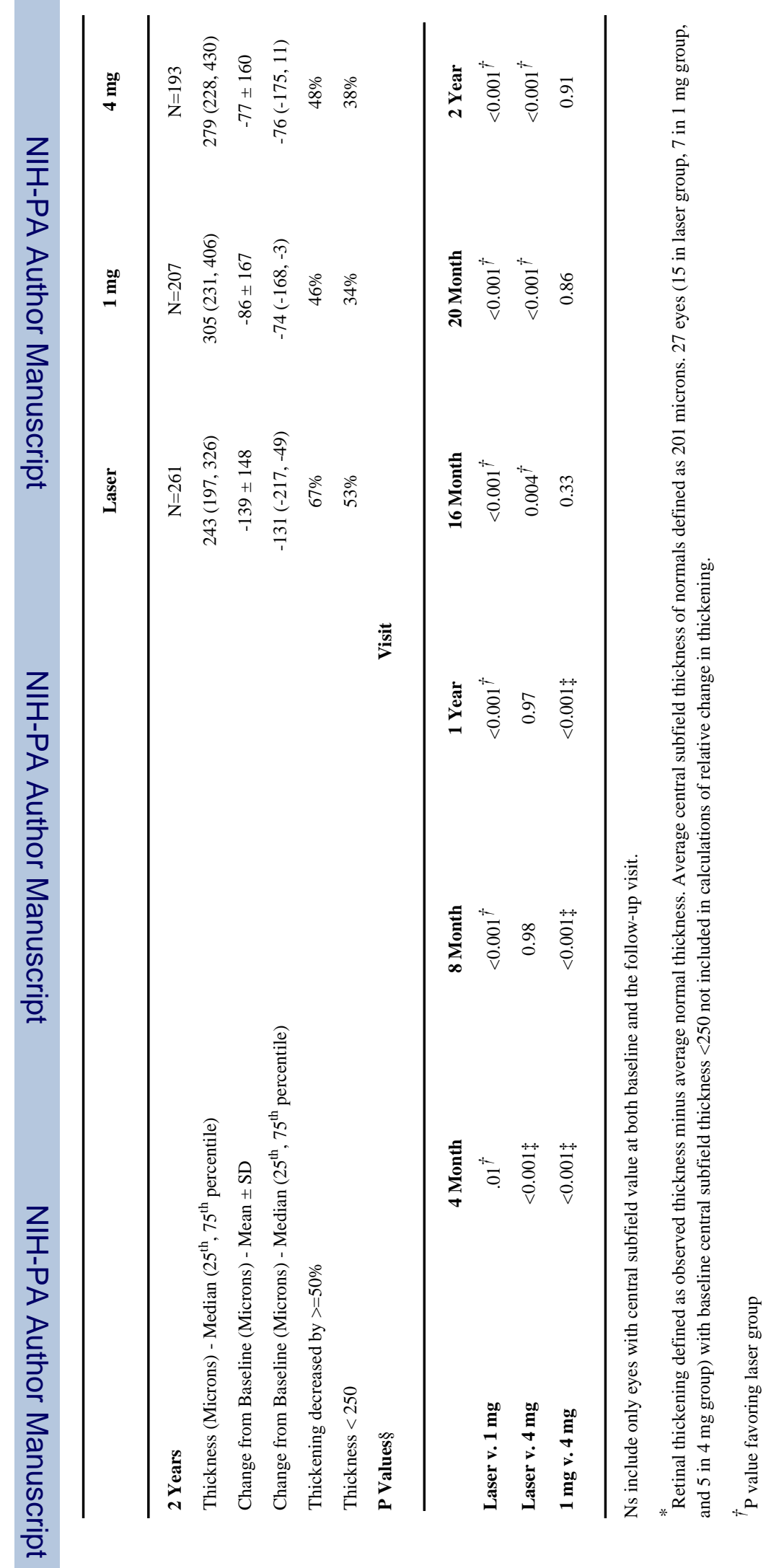

Ophthalmology. Author manuscript; available in PMC 2009 September 22. 
Table 7

Retinal Thickening* at 2 Years Overall and Stratified by Baseline Central Subfield Thickness

\begin{tabular}{|c|c|c|c|}
\hline Overall & Laser & $1 \mathrm{mg}$ & $4 \mathrm{mg}$ \\
\hline Central Subfield & $\mathrm{N}=261$ & $\mathrm{~N}=207$ & $\mathrm{~N}=193$ \\
\hline $\begin{array}{l}\text { Thickness (Microns) - Median ( } 25^{\text {th }}, 75^{\text {th }} \\
\text { percentile) }\end{array}$ & $243(197,326)$ & $305(231,406)$ & $279(228,430)$ \\
\hline $\begin{array}{l}\text { Change from Baseline (Microns) - Mean } \pm \\
\text { Standard Deviation }(\mathrm{SD})^{\dagger}\end{array}$ & $-139 \pm 148$ & $-86 \pm 167$ & $-77 \pm 160$ \\
\hline $\begin{array}{l}\text { Change from Baseline (Microns) - Median } \\
\left(25^{\text {th }}, 75^{\text {th }} \text { percentile }\right)\end{array}$ & $-131(-217,-49)$ & $-74(-168,-3)$ & $-76(-175,11)$ \\
\hline Thickening decreased by $>=50 \%^{\dagger}$ & $67 \%$ & $46 \%$ & $48 \%$ \\
\hline Thickness $<250^{\dagger}$ & $53 \%$ & $34 \%$ & $38 \%$ \\
\hline Retinal Volume & $\mathrm{N}=164$ & $\mathrm{~N}=133$ & $\mathrm{~N}=120$ \\
\hline Change from Baseline - Mean $\pm \mathrm{SD}^{\dagger}$ & $-1.4 \pm 1.7$ & $-0.7 \pm 1.7$ & $-0.4 \pm 1.7$ \\
\hline $\begin{array}{l}\text { Change from Baseline - Median }\left(25^{\text {th }}, 75^{\text {th }}\right. \\
\text { percentile })\end{array}$ & $-1.1(-2.2,-0.4)$ & $-0.6(-1.3,0.1)$ & $-0.6(-1.4,0.4)$ \\
\hline
\end{tabular}

Baseline Thickness < 400 Microns

\begin{tabular}{|c|c|c|c|}
\hline Central Subfield & $\mathrm{N}=139$ & $\mathrm{~N}=98$ & $\mathrm{~N}=104$ \\
\hline $\begin{array}{l}\text { Thickness (Microns) - Median }\left(25^{\text {th }}, 75^{\text {th }}\right. \\
\text { percentile) }\end{array}$ & $235(198,288)$ & $265(225,341)$ & $263(227,349)$ \\
\hline Change from Baseline (Microns) - Mean \pm SD & $-74 \pm 90$ & $-32 \pm 104$ & $-20 \pm 124$ \\
\hline $\begin{array}{l}\text { Change from Baseline (Microns) - Median } \\
\left(25^{\text {th }}, 75^{\text {th }} \text { percentile) }\right.\end{array}$ & $-86(-137,-18)$ & $-36(-101,18)$ & $-42(-102,24)$ \\
\hline Thickening decreased by $>=50 \%$ & $64 \%$ & $46 \%$ & $47 \%$ \\
\hline Thickness $<250$ & $60 \%$ & $42 \%$ & $44 \%$ \\
\hline Retinal Volume & $\mathrm{N}=90$ & $\mathrm{~N}=61$ & $\mathrm{~N}=71$ \\
\hline Change from Baseline - Mean \pm SD & $-0.8 \pm 1.3$ & $-0.4 \pm 0.8$ & $-0.2 \pm 1.5$ \\
\hline $\begin{array}{l}\text { Change from Baseline- Median }\left(25^{\text {th }}, 75^{\text {th }}\right. \\
\text { percentile) }\end{array}$ & $-0.6(-1.4,-0.2)$ & $-0.2(-0.8,0.1)$ & $-0.5(-1.2,0.3)$ \\
\hline \multicolumn{4}{|l|}{ Baseline Thickness 400-500 Microns } \\
\hline Central Subfield & $\mathrm{N}=58$ & $\mathrm{~N}=55$ & $\mathrm{~N}=49$ \\
\hline $\begin{array}{l}\text { Thickness (Microns) - Median }\left(25^{\text {th }}, 75^{\text {th }}\right. \\
\text { percentile) }\end{array}$ & $243(189,365)$ & $352(239,406)$ & $326(234,440)$ \\
\hline Change from Baseline (Microns) - Mean $\pm \mathrm{SD}$ & $-154 \pm 129$ & $-80 \pm 162$ & $-91 \pm 147$ \\
\hline $\begin{array}{l}\text { Change from Baseline (Microns) - Median } \\
\left(25^{\text {th }}, 75^{\text {th }} \text { percentile) }\right.\end{array}$ & $-193(-251,-69)$ & $-92(-177,-29)$ & $-105(-200,5)$ \\
\hline Thickening decreased by $>=50 \%$ & $67 \%$ & $44 \%$ & $49 \%$ \\
\hline Thickness $<250$ & $52 \%$ & $27 \%$ & $29 \%$ \\
\hline Retinal Volume & $\mathrm{N}=35$ & $\mathrm{~N}=36$ & $\mathrm{~N}=34$ \\
\hline Change from Baseline - Mean \pm SD & $-1.6 \pm 1.6$ & $-0.5 \pm 1.2$ & $-0.5 \pm 1.6$ \\
\hline $\begin{array}{l}\text { Change from Baseline }- \text { Median }\left(25^{\text {th }}, 75^{\text {th }}\right. \\
\text { percentile) }\end{array}$ & $-1.3(-2.5,-0.7)$ & $-0.7(-1.2,0.1)$ & $-0.8(-1.4,0.2)$ \\
\hline
\end{tabular}




\begin{tabular}{|c|c|c|c|}
\hline Overall & Laser & $1 \mathrm{mg}$ & $4 \mathrm{mg}$ \\
\hline \multicolumn{4}{|l|}{ Baseline Thickness > 500 Microns } \\
\hline Central Subfield & $\mathrm{N}=64$ & $\mathrm{~N}=54$ & $\mathrm{~N}=40$ \\
\hline $\begin{array}{l}\text { Thickness (Microns) - Median ( } 25^{\text {th }}, 75^{\text {th }} \\
\text { percentile) }\end{array}$ & $301(199,423)$ & $408(245,552)$ & $367(223,563)$ \\
\hline Change from Baseline (Microns) - Mean \pm SD & $-265 \pm 177$ & $-192 \pm 211$ & $-209 \pm 178$ \\
\hline $\begin{array}{l}\text { Change from Baseline (Microns) - Median } \\
\left(25^{\text {th }}, 75^{\text {th }} \text { percentile }\right)\end{array}$ & $-259(-373,-169)$ & $-204(-355,-52)$ & $-247(-322,-97)$ \\
\hline Thickening decreased by $>=50 \%$ & $72 \%$ & $48 \%$ & $50 \%$ \\
\hline Thickness $<250$ & $41 \%$ & $26 \%$ & $33 \%$ \\
\hline Retinal Volume & $\mathrm{N}=39$ & $\mathrm{~N}=36$ & $\mathrm{~N}=15$ \\
\hline Change from Baseline - Mean \pm SD & $-2.5 \pm 2.0$ & $-1.6 \pm 2.6$ & $-0.7 \pm 2.6$ \\
\hline $\begin{array}{l}\text { Change from Baseline -Median }\left(25^{\text {th }}, 75^{\text {th }}\right. \\
\text { percentile) }\end{array}$ & $-2.4(-3.7,-1.2)$ & $-1.3(-3.3,-0.6)$ & $-1.7(-2.5,1.1)$ \\
\hline
\end{tabular}

Ns include only eyes with a central subfield or retinal volume value at both baseline and the follow-up visit.

*

Retinal thickening defined as observed thickness minus average normal thickness. Average central subfield thickness of normals defined as 201 microns. 27 eyes (15 in laser group, 7 in $1 \mathrm{mg}$ group, and 5 in $4 \mathrm{mg}$ group) with baseline central subfield thickness <250 not included in calculations of relative change in thickening.

${ }^{\dagger} \mathrm{P}$ values (not adjusted for multiple comparisons) for treatment group comparisons of laser v. $1 \mathrm{mg}$, laser v. $4 \mathrm{mg}$, and $1 \mathrm{mg}$ v. $4 \mathrm{mg}$ are as follows: Change in central subfield from baseline: $<0.001,<0.001,0.91$; percentage with central subfield thickening reduced by $50 \%$ or more: $<0.001,<0.001,0.60$; percentage with central subfield thickness $<250$ microns: $<0.001,<0.001,0.55$; change in retinal volume from baseline: $<0.001,<0.001,0.44$ 
Table 8

Major Ocular Adverse Events During Two Years of Follow Up

\begin{tabular}{|c|c|c|c|}
\hline & $\begin{array}{c}\text { Laser } \\
\mathrm{N}=330 \text { eyes } \\
\mathrm{N}=\mathbf{2 3}(4 \mathrm{mg}) \\
\text { injections }\end{array}$ & $\begin{array}{c}1 \mathrm{mg} \\
\mathrm{N}=256 \text { eyes } \\
\mathrm{N}=\mathbf{8 4 1} \text { injections }\end{array}$ & $\begin{array}{c}4 \mathrm{mg} \\
\mathrm{N}=254 \text { eyes } \\
\mathrm{N}=\mathbf{7 4 2} \text { injections }\end{array}$ \\
\hline Endophthalmitis ${ }^{*} N$ & 0 & 0 & 0 \\
\hline Pseudoendophthalmitis $N$ & 0 & 0 & 0 \\
\hline Retinal detachment ${ }^{\dagger} N$ & 2 & 2 & 4 \\
\hline Retinal vein occlusion ${ }^{\dagger} N$ & 3 & 1 & 2 \\
\hline Retinal artery occlusion ${ }^{\dagger} N$ & 1 & 0 & 0 \\
\hline Anterior ischemic optic neuropathy ${ }^{\dagger} N$ & 0 & 1 & 0 \\
\hline Vitrectomy $N^{\ddagger}$ & 31 & 26 & 19 \\
\hline \multicolumn{4}{|l|}{ Elevated Intraocular Pressure/Glaucoma $N(\%)$} \\
\hline Increase $>=10 \mathrm{mmHg}$ from baseline $\mathrm{s}^{\S}$ & $12(4 \%)$ & $41(16 \%)$ & $85(33 \%)$ \\
\hline $\mathrm{IOP}>=30 \mathrm{mmHg} \S$ & $3(1 \%)$ & $22(9 \%)$ & $53(21 \%)$ \\
\hline Initiation of IOP-lowering medication ${ }^{\S}$ & $25(8 \%)$ & $31(12 \%)$ & $76(30 \%)$ \\
\hline Open angle glaucoma & $2(1 \%)$ & $2(1 \%)$ & $7(3 \%)$ \\
\hline Glaucoma filtering surgery & 0 & 0 & $2(1 \%)$ \\
\hline Laser trabeculoplasty & 0 & 0 & $1(<1 \%)$ \\
\hline Ciliary body destruction & 0 & 0 & $1(<1 \%)$ \\
\hline No. of eyes meeting one or more of the above & $33(10 \%)$ & $51(20 \%)$ & $102(40 \%)$ \\
\hline \multicolumn{4}{|l|}{ Cataract Surgery ${ }^{* *}$} \\
\hline \# phakic at baseline & $\mathrm{N}=262$ & $\mathrm{~N}=\mathbf{2 0 3}$ & $\mathrm{N}=197$ \\
\hline $\mathrm{N}(\%)$ with cataract surgery & $34(13 \%)$ & $47(23 \%)$ & $101(51 \%)$ \\
\hline \multicolumn{4}{|c|}{ * one case of endophthalmitis occurred following vitrectomy, not related to injection of study drug } \\
\hline \multicolumn{4}{|l|}{$\dagger_{\text {not necessarily related to treatment }}$} \\
\hline \multicolumn{4}{|c|}{$F_{\text {includes vitrectomy for diabetic macular edema, vitreous hemorrhage or other cause }}$} \\
\hline$\S_{\text {at any follow-up visit through the two-year exam }}$ & & & \\
\hline
\end{tabular}

